\title{
Establishing the impact of model surfactants on cloud condensation nuclei activity of sea spray aerosol mimics
}

\author{
Sara D. Forestieri ${ }^{1, a}$, Sean M. Staudt ${ }^{2}$, Thomas M. Kuborn ${ }^{2}$, Katharine Faber ${ }^{3}$ Christopher R. Ruehl $^{4}$, \\ Timothy H. Bertram ${ }^{2}$, and Christopher D. Cappa ${ }^{1}$ \\ ${ }^{1}$ Department of Civil and Environmental Engineering, University of California, Davis, CA, USA \\ ${ }^{2}$ Department of Chemistry, University of Wisconsin, Madison, WI, USA \\ ${ }^{3}$ Department of Chemistry, Carleton College, Northfield, MN, USA \\ ${ }^{4}$ California Air Resources Board, Sacramento, CA, USA \\ anow at: California Air Resources Board, Sacramento, CA, USA
}

Correspondence: Christopher D. Cappa (cdcappa@ucdavis.edu)

Received: 24 February 2018 - Discussion started: 2 March 2018

Revised: 13 June 2018 - Accepted: 20 June 2018 - Published: 7 August 2018

\begin{abstract}
Surface-active compounds present in aerosols can increase their cloud condensation nuclei $(\mathrm{CCN})$ activation efficiency by reducing the surface tension $(\sigma)$ in the growing droplets. However, the importance of this effect is poorly constrained by measurements. Here we present estimates of droplet surface tension near the point of activation derived from direct measurement of droplet diameters using a continuous flow streamwise thermal gradient chamber (CFSTGC). The experiments used sea spray aerosol (SSA) mimics composed of $\mathrm{NaCl}$ coated by varying amounts of (i) oleic acid, palmitic acid or myristic acid, (ii) mixtures of palmitic acid and oleic acid, and (iii) oxidized oleic acid. Significant reductions in $\sigma$ relative to that for pure water were observed for these mimics at relative humidity $(\mathrm{RH})$ near activation ( $\sim 99.9 \%$ ) when the coating was sufficiently thick. The calculated surface pressure $\left(\pi=\sigma_{\mathrm{H}_{2} \mathrm{O}}-\sigma_{\text {observed }}\right)$ values for a given organic compound or mixture collapse onto one curve when plotted as a function of molecular area for different $\mathrm{NaCl}$ seed sizes and measured $\mathrm{RH}$. The observed critical molecular area $\left(A_{0}\right)$ for oleic acid determined from droplet growth was similar to that from experiments conducted using macroscopic solutions in a Langmuir trough. However, the observations presented here suggest that oleic acid in microscopic droplets may exhibit larger $\pi$ values during monolayer compression. For myristic acid, the observed $A_{0}$ compared well to macroscopic experiments on a fresh subphase, for which dissolution has an important impact. A significant kinetic limitation to water uptake was observed for $\mathrm{NaCl}$ particles coated with pure palmitic acid, likely as a result of
\end{abstract}

palmitic acid (with coating thicknesses ranging from 67 to $132 \mathrm{~nm}$ ) being able to form a solid film. However, for binary palmitic-acid-oleic-acid mixtures there was no evidence of a kinetic limitation to water uptake. Oxidation of oleic acid had a minor impact on the magnitude of the surface tension reductions observed, potentially leading to a slight reduction in the effect compared to pure oleic acid. A CCN counter was also used to assess the impact on critical supersaturations of the substantial $\sigma$ reductions observed at very high $\mathrm{RH}$. For the fatty-acid-coated $\mathrm{NaCl}$ particles, when the organic fraction $\left(\varepsilon_{\text {org }}\right)$ was $>0.90$ small depressions in critical supersaturation were observed. However, when $\varepsilon_{\text {org }}$ $<0.90$ the impact on critical supersaturation was negligible. Thus, for the fatty acids considered here, the substantial $\sigma$ reductions observed at high $\mathrm{RH}$ values just below activation have limited impact on the ultimate critical supersaturation. A surface film model is used to establish the properties that surface-active organic molecules must have if they are to ultimately have a substantial impact on the activation efficiency of SSA. To influence activation, the average properties of surface-active marine-derived organic molecules must differ substantially from the long-chain fatty acids examined, having either smaller molecular volumes or larger molecular areas. The model results also indicate that organic-compounddriven surface tension depression can serve to buffer the critical supersaturation against changes to the organic-to-salt ratio in particles in which the organic fraction is sufficiently large. 


\section{Introduction}

Surface-active organic matter present in atmospheric aerosols has received considerable attention given its important role in heterogeneous chemistry (Knopf et al., 2005; Shaloski et al., 2017), aerosol water uptake and evaporation (Davies et al., 2013), and potential impact on the ability of particles to activate into cloud droplets (Ruehl et al., 2016; Ovadnevaite et al., 2017). Amphiphilic, surface-active species have the potential to lower surface tension of a growing droplet, relative to pure water, due to their presence at the air-water interface. Through the Kelvin effect, this reduction in surface tension can, in theory, reduce the critical supersaturation, thereby increasing particle cloud condensation nuclei (CCN) activation efficiency (Farmer et al., 2015).

The importance of surface tension depression, however, remains contentious given the difficulty in quantifying surface tension in microscopic droplets directly (Broekhuizen et al., 2004, 2006; Mircea et al., 2005; Henning et al., 2005; Wex et al., 2009; Gray Bé et al., 2017; Good et al., 2010a, b; Jurányi et al., 2010; Fuentes et al., 2011; Duplissy et al., 2008; Prisle et al., 2011; Petters and Kreidenweis, 2013; Sareen et al., 2013; Giordano et al., 2013; Moore et al., 2008; Li et al., 1998). Surface tension reductions have been observed in macroscopic solutions of organic matter extracted form aerosols when the organic concentration is sufficiently large (Facchini et al., 1999; Noziere et al., 2014). Calculations of critical supersaturation based on such measurements indicate a strong potential for organic compounds to influence cloud formation and properties (Facchini et al., 1999; Mircea et al., 2002). There have also been direct single particle surface tension measurements for aerosols at sub-saturated humidities (Lee et al., 2017). However, it has been suggested that the effects of surface tension lowering on cloud droplet activation are offset by depletion of solutes from the bulk solution as they partition to the surface of microscopic droplets having high surface-area-to-volume ratios (Prisle et al., 2010; AsaAwuku et al., 2009; Sorjamaa et al., 2004).

One challenge in assessing the potential influence of surface tension depression on CCN activity has been the lack of unambiguous evidence for the impact of surface tension on droplet activation. Recent work, using a custom-built continuous flow streamwise thermal gradient chamber (CFSTGC) to measure the sizes of droplets around $100 \%$ relative humidity (RH), has allowed for more direct estimates of the surface tension depression in microscopic droplets at humidities relevant to cloud droplet formation. The size of droplets around $100 \% \mathrm{RH}$ is sensitive to deviations in surface tension from that of pure water, much more so than at lower relative humidities. Thus, droplet size measurements can be used to infer surface tension values. Using this method, it was determined that the surface tension of droplets was substantially reduced below that of pure water at $\mathrm{RH} \sim 100 \%$ for binary mixtures of individual surface-active compounds and ammonium sulfate and for $\mathrm{NaCl}$ coated with secondary organic aerosol when the coatings were sufficiently thick (Ruehl and Wilson, 2014; Ruehl et al., 2012). The reduction in surface tension at a given RH caused the droplets to grow larger than predicted if the surface tension was assumed to be that of pure water (Ruehl et al., 2016).

One particle type where surface tension impacts on cloud droplet activation might be of particular importance is with sea spray aerosol (SSA) particles. There is indirect evidence that surface tension reductions affect the efficiency of SSA particle activation. For example, Collins et al. (2016) observed high hygroscopicity parameters $(\kappa>0.7)$ for small SSA particles $(<150 \mathrm{~nm})$ generated during a suite of microcosm phytoplankton bloom, up to very high chlorophyll $a$ concentrations in the source water (a marker for biological activity), yet no correlation between $\kappa$ and biological activity was observed. Although Collins et al. (2016) did not measure the particle composition it seems likely that the organic fraction of the particles was large due to the high biological activity (O'Dowd et al., 2004). Additionally, very large organic fractions were separately observed for small particles $(<200 \mathrm{~nm})$ for a similar microcosm experiment (Deane et al., 2018). The potential for substantial surface tension lowering was invoked to explain the high $\kappa$ values observed. However, Fuentes et al. (2011) performed experiments using seawater enriched in marine exudates and found no evidence that surface tension reduction impacted $\mathrm{CCN}$ activation, observing instead a slight decrease in the CCN activation efficiency with increasing organic content, although the measured organic fractions of their particles were relatively low $(<40 \%)$ and therefore would not enhance $\mathrm{CCN}$ activity if this organic matter formed a compressed film on the droplet surface (Ruehl et al., 2016).

To better understand the impact of surface-active organic species on SSA particle activation efficiency, and on droplet activation in general, we report on measurements of droplet sizes at $\mathrm{RH}$ values just below activation for $\mathrm{NaCl}$ particles coated with varying amounts of marine-relevant organic compounds, specifically long-chain fatty acids. These experiments were done as part of the MadFACTS campaign (Madison Fatty Acid Coating Thickness Study). Long-chain fatty acids are an important class of organic compounds found in submicron SSA particles (Cochran et al., 2016, 2017). Since this class of organic species is surface active (Schwier et al., 2012) they have the potential to enhance observed CCN activation efficiency by depressing surface tension, but the overall effect of fatty acid addition on CCN activation efficiency of salt particles has been shown to be minimal (Nguyen et al., 2017). Petters and Petters (2016) additionally investigated binary salt + nonionic surfactant mixtures and observed that the $\mathrm{CCN}$ activation efficiency was, in some cases, actually suppressed relative to ideal mixing. Similarly, Prisle et al. (2010) observed that the CCN activation efficiency of binary $\mathrm{NaCl}+$ ionic surfactant mixtures was reasonably well described assuming the surfactants to be fully soluble with no impact on surface tension. In this work we will clarify 

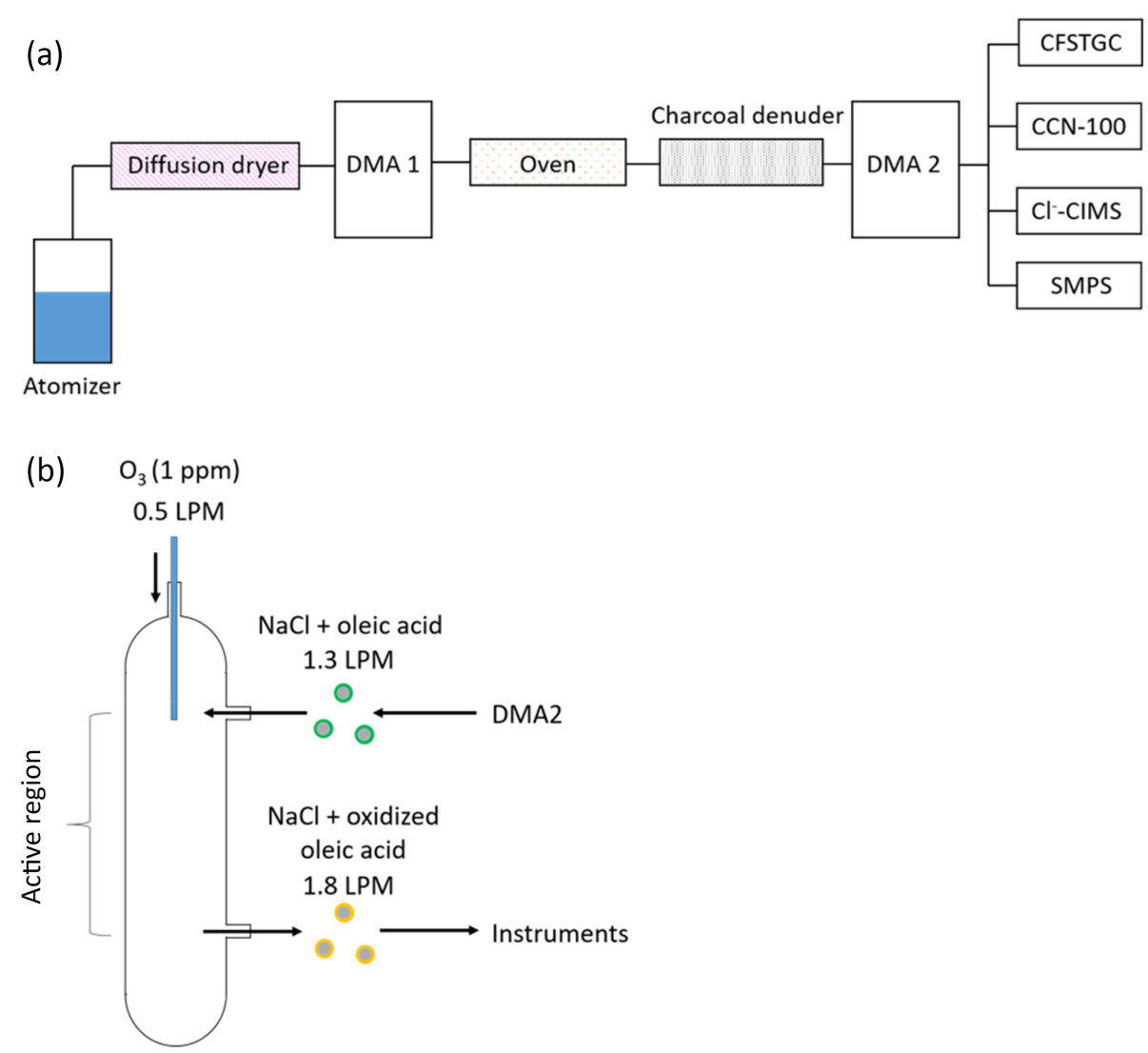

Figure 1. (a) Experimental schematic for non-oxidized experiments. (b) Flow tube schematic for $\mathrm{NaCl}+$ oxidized oleic acid experiments. The blue line illustrates the movable injector.

why such highly surface-active species can have, and in the case of fatty acids do have, little impact $\mathrm{CCN}$ activation efficiency. Additionally, since particles in the ambient atmosphere are composed of complex mixtures of organic species, the role of mixtures was investigated by comparing singlecomponent and binary surfactant systems and by comparing oxidized and unoxidized systems. These measurements were used to estimate the surface tension of the droplets as a function of the relative abundances of $\mathrm{NaCl}$ and the organic component(s) at a given $\mathrm{RH}$, or as a function of RH for a fixed dry particle composition. We connect these near-activation surface tension measurements to the surface tension estimated at activation with a traditional CCN counter to assess whether the observed reductions in surface tension significantly affect critical supersaturations for these chemical systems.

\section{Methods}

A suite of instrumentation was used to generate sea spray aerosol mimics and monitor their hygroscopic properties and chemical composition. A general schematic of the experimental setup is shown in Fig. 1.

\subsection{Particle generation and processing}

Polydisperse $\mathrm{NaCl}$ particles were generated from a constant output atomizer (TSI Inc.) containing a $0.05 \mathrm{M}$ solution of $\mathrm{NaCl}$ (99\% purity). The air stream was dried with a diffusion denuder to $<20 \% \mathrm{RH}$. The particles were size selected using a DMA (differential mobility analyzer; TSI Inc.; model 3081) with mobility diameters ranging from 150 to $200 \mathrm{~nm}$. The sheath to aerosol flow ratio was $10: 1$ to provide a relatively narrow distribution. The monodisperse particles were passed through an oven containing an aluminum sample holder with surface-active organic compounds. The organic compounds used were myristic acid (99\% purity; Sigma Aldrich), palmitic acid (99\% purity; Sigma Aldrich), and oleic acid (90 or $99 \%$ purity; Sigma Aldrich). Myristic acid and palmitic acid are saturated fatty acids containing 14 and 16 carbons, respectively, and exist as waxy solids at room temperatures. Oleic acid is an unsaturated fatty acid that exists as a liquid at room temperature and contains 18 carbons. For mixed surfactant studies, a sample holder containing known amounts of each organic compound (molar ratio $1: 1$ ) was added to the oven. In the oven, the organic compounds evaporated into the vapor phase. Upon exiting the oven, the air stream cooled and the organic compounds condensed onto 
the $\mathrm{NaCl}$ particles, resulting in surfactant-coated $\mathrm{NaCl}$ particles. Oven temperatures ranged from $85^{\circ} \mathrm{C}$ for thin coatings $(\sim 30 \mathrm{~nm})$ to $130^{\circ} \mathrm{C}$ for thick coatings $(>100 \mathrm{~nm})$. A charcoal denuder was placed after the oven to remove residual vapor from the air stream. A second DMA was used to select particles of a given size from the coated distribution and served to remove small nucleated particles composed purely of the organic compound(s). Note that for the second DMA the neutralizer ( $\mathrm{Kr}-85)$ was bypassed, ensuring that only particles containing $\mathrm{NaCl}$ were sampled. Flow was then split isokinetically through a flow splitter (TSI Inc.; model 370800) to the various instrumentations.

For oxidation experiments, oleic-acid-coated $\mathrm{NaCl}$ particles were exposed to $\mathrm{O}_{3}$ in a vertical glass flow tube. Particles were introduced into the flow tube via a side port located $19 \mathrm{~cm}$ below the top of the tube and exited through a side port $77 \mathrm{~cm}$ below the inlet. Ozone was injected through a moveable stainless steel injector that passed through the top of the flow tube. The exit of the injector was positioned between the particle inlet and exit ports, hereafter referred to as the active region. The residence time was varied by moving the injector position and calculated based on the distance between the injector and the flow tube exit. Total flow through the flow tube was 1.8 SLPM, with 0.5 and 1.3 SLPM for the $\mathrm{O}_{3}$ and particle streams, respectively. The injected $\mathrm{O}_{3}$ concentration was $1 \mathrm{ppm}$, resulting in an estimated concentration of $278 \mathrm{ppb}$ in the flow tube, after dilution. Residence times calculated based on the flow rate and flow tube volume were 0,20 , and $57 \mathrm{~s}$. However, the air was sampled from the side of the flow tube and so the effective residence time was longer and was never as short as $0 \mathrm{~s}$ and the minimum ozone exposure was actually greater than zero. There was a bypass channel for the flow tube to monitor particle size and hygroscopicity prior to the flow tube experiments; these bypass measurements correspond to an actual ozone exposure of zero. The estimated ozone exposure ranged from $1.4 \times 10^{14}(20 \mathrm{~s})$ to $3.9 \times 10^{14}$ (57 s) molecules $\mathrm{cm}^{-3} \mathrm{~s}$ for nonzero residence times. These are likely lower limits to the true $\mathrm{O}_{3}$ exposure, given the nonideal flow within the flow tube resulting from the side sampling. Also note that a stainless steel injector was used, and thus the $\mathrm{O}_{3}$ concentration in the flow tube was likely somewhat lower than the estimated value.

\subsection{Hygroscopicity measurements}

Wet droplet diameter distributions at RH values near $100 \%$ (both above and below) were measured by a CFSTGC, described in detail by Ruehl et al. (2010). Briefly, particles are humidified in a temperature-controlled tube lined with wetted filter paper $(102 \mathrm{~cm}$ in length, with an effective inner diameter of $2.2 \mathrm{~cm}$ ). The temperature gradient across the length of the tube could either be positive or negative, allowing for both sub- and supersaturated RH values to be achieved (Roberts and Nenes, 2005), with a working range from 99.8 to $100.06 \%$. Before exiting the CFSTGC, wet droplet size distributions and velocity were measured with a phase-doppler interferometer (PDI; Artium Technologies, Inc.). The particular configuration of this CFSTGC instrument allows for accurate and precise determination of droplet diameters at a known $\mathrm{RH}$ value prior to activation. The total flow through the chamber was 0.5 SLPM, with a sheath: sample flow ratio of 2.33 . The total residence time of the chamber centerline was $\sim 22 \mathrm{~s}$. The mode diameter for each measurement was obtained by fitting the numberweighted wet droplet distribution to a Gaussian curve using a function in the data-processing program Igor (Wavemetrics, v6.37), with each scan consisting of $\sim 1000$ droplet measurements. Average temperatures in the CFSTGC ranged from 20 to $25^{\circ} \mathrm{C}$. The absolute temperatures were varied from day to day due to fluctuations in the room temperature and were selected to prevent condensation in the detection chamber. However, since the instrument $\mathrm{RH}$ depends primarily on $\Delta T$ and not absolute $T$, these variations do not affect instrument performance.

RH in the CFSTGC was calibrated by sampling sizeselected salt particles composed of either $\mathrm{NaCl}$ or ammonium sulfate. The $\kappa$-Köhler equation (Petters and Kreidenweis, 2007) was then used to calculate RH:

$\frac{\mathrm{RH}}{100}=\frac{D_{\text {wet }}^{3}-D_{\text {dry }}^{3}}{D_{\text {wet }}^{3}-D_{\text {dry }}^{3}\left(1-\kappa_{\text {avg }}\right)} \exp \left[\frac{4 \sigma V_{\mathrm{H}_{2} \mathrm{O}}}{k T D_{\text {wet }}}\right]$,

where $D_{\text {wet }}$ is the measured wet diameter, $D_{\text {dry }}$ is the dry diameter, $\kappa$ is the known hygroscopicity parameter, $\sigma$ is surface tension, $V_{\mathrm{H}_{2} \mathrm{O}}$ is the molar volume of water in the droplet, $k$ is the Boltzmann constant, and $T$ is temperature. The first term corresponds to the Raoult effect, which accounts for reductions in water activity to the dissolution of solutes. The effective solubility of a given species is parameterized by the $\kappa$ parameter, which ranges here from $\sim 0$ (insoluble) to 1.4 (very soluble). The exponential, or Kelvin, term accounts for the enhanced vapor pressure over a curved surface and is proportional to $\sigma$. For the calibrations, $\sigma$ is assumed to be equal to that of water. This is reasonable given the dilute concentrations of salt $(\sim 0.05 \mathrm{M})$ in the aqueous droplets and the lack of surface-active species. The accuracy of RH calibrations depends on the assumed $\kappa$ values and shape-correction factors of the calibration salts. The RH values were calculated from Eq. (1) assuming that $\kappa$ values were 1.3 and 0.61 for $\mathrm{NaCl}$ and ammonium sulfate, respectively (Petters and Kreidenweis, 2007). $\kappa$ values can vary with particle size and $\mathrm{RH}$, due to variations in activity. The use of these specific values is reasonable for the particle sizes $(>100 \mathrm{~nm})$ and $\mathrm{RH}$ range (>99.9\% RH) considered in our experiments (Topping et al., 2016). An uncertainty of \pm 0.05 in $\kappa$ corresponds to an uncertainty in $\mathrm{RH}$ of ca. $0.01 \%$ (for $\mathrm{NaCl}$ ) and $0.02 \%$ (for ammonium sulfate) around $99.9 \% \mathrm{RH}$, but of $<0.01 \%$ at RH values near the critical supersaturation. The shape-correction factors were 1.08 and 1.04 for $\mathrm{NaCl}$ and ammonium sulfate, respectively (Mikhailov et al., 2004; Zelenyuk et al., 2006). 
As such, the uncertainty for RH in the CFSTGC was characterized by calibrating the chamber with both size-selected $\mathrm{NaCl}$ and ammonium sulfate, switching between the two salts every 3-5 min. Results of this comparison are shown in Fig. S1 in the Supplement. The slope of the linear fit was 1.00 , with the majority of the data falling within $0.025 \%$ of the $1: 1$ line. During experiments with $\mathrm{NaCl}$ particles coated with organic compounds, the RH was calibrated multiple times a day with either never-coated particles or with $\mathrm{NaCl}$ particles where the organic coating was completely removed by passing the particles through a thermodenuder at $250^{\circ} \mathrm{C}$. (No difference was found between never-coated and thermally denuded $\mathrm{NaCl}$ particles.) By calibrating throughout the day, noise due to RH drift was minimized. Most experiments were conducted holding both $\mathrm{RH}$ and the $\mathrm{NaCl}$ seed size constant while varying the amount of organic coating. For one experiment with oleic acid as a coating, the composition (or coating amount) of the particles was held constant, while RH was varied to characterize how droplet size varied leading up to the point of activation. In this manner, a Köhler curve is mapped out (Ruehl et al., 2016).

For a subset of experiments, the number of particles that activate into cloud droplets at a given supersaturation was characterized with a CCN counter (Droplet Measurement Technologies model CCN-100) (Roberts and Nenes, 2005). Total particle concentrations were measured concurrently with a condensation particle counter (CPC; TSI Inc. model 3787). The combination of these measurements allowed for the calculation of the fraction of activated particles $\left(f_{\text {act }}\right)$ as a function of supersaturation $(s=\mathrm{RH} / 100-1)$, with scanned supersaturation values ranging from 0.03 to $0.1 \%$. The critical supersaturation $\left(s_{\mathrm{c}}\right)$ was determined by fitting a sigmoidal function to $f_{\text {act }}$ versus $s$. The apparent hygroscopicity parameter (Petters and Kreidenweis, 2007) was then calculated using the following equation:

$\kappa_{\mathrm{app}}=\frac{4 A^{3}}{27 D_{\mathrm{dry}}^{3} \ln ^{2} S_{\mathrm{c}}}$ and $A^{*}=\frac{4 \sigma M_{\mathrm{W}}}{R T \rho_{\mathrm{W}}}$,

where $S_{\mathrm{c}}=s_{\mathrm{c}}+1, M_{\mathrm{W}}$ is the molecular weight of water, $D_{\mathrm{dry}}$ is the dry diameter, $\sigma$ is surface tension, $\rho_{\mathrm{W}}$ is the density of water, $R$ is the ideal gas constant, and $T$ is temperature. In using Eq. (2), it is assumed here that $\sigma$ is equal to that of water $\left(72 \mathrm{mN} \mathrm{m}^{-1}\right)$. Since the true value of $\sigma$ may deviate from $72 \mathrm{mN} \mathrm{m}^{-1}$, we refer to the derived $\kappa$ as the apparent $\kappa$ (or $\left.\kappa_{\text {app }}\right)$. The supersaturation as a function of temperature gradient in the instrument was calibrated with $\mathrm{NaCl}$ in the scanned range (Fig. S2 in the Supplement). The particle sizes used in the calibration were shape corrected. Petters and Kreidenweis (2007) note that Eq. (2) is only valid when $\kappa>0.2$. The use of Eq. (2) will not impact our calibrations, given the use of $\mathrm{NaCl}$. The use of Eq. (2) for determination of $\kappa_{\text {app }}$ for experiments with particles having large organic fractions, for which $\kappa_{\text {app }}<0.2$, can lead to a small overestimate in $\kappa_{\text {app }}$. Comparison of the $\kappa_{\text {app }}$ determined from Eq. (2) compared to the full expression indicates that the error introduced is introduced is $<0.4 \%$ in $\kappa_{\text {app }}$, corresponding to an absolute value of $<0.0003$ for $\kappa_{\text {app }}<0.07$ (approximately the lowest value from the $\mathrm{NaCl}$-organic-compound mixtures used here).

\subsection{Size and composition}

Diameters of the size-selected, dry, coated particles were measured with a scanning mobility particle sizer (SMPS; consisting of a DMA TSI model 3081 and TSI CPC 3775). Example size distributions for uncoated, thinly coated, and thickly coated particles are shown in Fig. S3 in the Supplement. Mode diameters were obtained by fitting a lognormal function to the obtained size distributions. The organic volume fraction was calculated as

$\varepsilon_{\text {org }}=\frac{\frac{\pi}{6} D_{\mathrm{tot}}^{3}-\frac{\pi}{6} D_{\mathrm{NaCl}}^{3}}{\frac{\pi}{6} D_{\mathrm{tot}}^{3}}$,

where $D_{\text {tot }}$ is the total coated diameter and $D_{\mathrm{NaCl}}$ is the diameter of the size-selected $\mathrm{NaCl}$ particles, adjusted for shape effects. Precision-based uncertainty for the selected diameter was assessed by size-selecting particles with one DMA and measuring the resulting size distribution. The mode diameter and the size-selected diameter agreed within $1 \%$. For a subset of experiments, a scanning electrical mobility sizer (SEMS; BMI, Inc.) was used to measure size distributions.

The organic composition was monitored with a chemical ionization mass spectrometer (CIMS) coupled with a thermal desorption chamber to vaporize the particle-phase organic coating (McNeill et al., 2008). The CIMS used $\mathrm{Cl}^{-}$, as opposed to $\mathrm{I}^{-}$, as the reagent ion so as to retain the ion-molecule adducts $\left(\mathrm{Cl}^{-} \cdot \mathrm{HA}\right)$ within the mass range of the quadrupole mass analyzer. After each experiment, the CIMS sampled particle-free air by setting the second DMA voltage to 0 , downstream of the oven, to characterize background gasphase concentrations. Each compound had a unique spectrum with an identifiable ion corresponding to the unfragmented parent compound. The counts for each compound were used to calculate relative abundances for the binary organic mixtures under the assumption that the sensitivity of the CIMS was the same for each carboxylic acid. When $\mathrm{I}^{-}$is used as the reagent ion, the CIMS method is somewhat more sensitive towards palmitic acid compared to oleic acid (Lee et al., 2014). If this difference in sensitivity similarly applies to the $\mathrm{Cl}^{-}$reagent ion then the relative abundance of palmitic acid will be underestimated by the assumption of equal sensitivities.

\subsection{Upper-limit surface pressure calculation}

The combination of $D_{\text {wet }}$ from the CFSTGC, the modecoated diameter $\left(D_{\text {dry }}\right)$, and the calibrated RH allows for the surface tension $(\sigma)$ of the droplets to be calculated for every individual measurement using Eq. (1). Since the particles were mixtures of $\mathrm{NaCl}$ and organic compounds, the $\kappa_{\text {avg }}$ term 
was calculated, assuming volume mixing, as

$\kappa_{\mathrm{avg}}=\varepsilon_{\mathrm{org}} \kappa_{\mathrm{org}}+\left(1-\varepsilon_{\mathrm{org}}\right) \kappa_{\mathrm{NaCl}}$.

The values of $\kappa_{\text {org }}$ and $\kappa_{\mathrm{NaCl}}$ were assumed to be 0 (Petters et al., 2016) and 1.3 (Petters and Kreidenweis, 2007), respectively. The use of Eq. (1) provides a lower-limit estimate of $\sigma$, since it is assumed that none of the organic component partitions into the bulk droplet and is present only at the surface. These values are therefore referred to as the lowerlimit $\sigma$. This model essentially assumes a phase separation between a water-free organic phase and water-rich inorganic phase, mimicking a permanent liquid-liquid phase separation (Ovadnevaite et al., 2017).

To facilitate the comparison between macroscopic surface tension studies and this work, the surface pressure $(\pi)$ was calculated from the observed $\sigma$ values as

$\pi=\sigma_{\mathrm{H}_{2} \mathrm{O}}-\sigma_{\mathrm{obs}}$,

where $\sigma_{\mathrm{H}_{2} \mathrm{O}}$ and $\sigma_{\mathrm{obs}}$ are the surface tension of water and the observed surface tension, respectively. The $\pi$ values calculated from Eq. (5) using the lower-limit $\sigma$ will thus be referred to as the upper-limit $\pi$ estimate. A corresponding molecular area $\left(A_{\mathrm{mlc}}\right)$, which is a measure of the inverse of concentration of surfactant at the interface, is calculated as

$A_{\mathrm{mlc}}=\frac{M W}{\rho \cdot N_{\mathrm{A}}}\left(\frac{6 \cdot D_{\mathrm{wet}}^{2}}{D_{\text {coat }}^{3}-D_{\text {seed }}^{3}}\right)$,

where $M W$ is the molecular weight, $\rho$ is the density of the organic compound, and $N_{\mathrm{A}}$ is Avogadro's number. The molecular area from Eq. (6) is a lower limit, as it assumes that all of the surfactant is at the surface. For experiments where $\mathrm{NaCl}$ was coated with two types of organic compounds, a molarweighted average of the molecular weight and density for each component was used to calculate molecular area.

\subsection{Surface and bulk partitioning}

Given the large surface-area-to-volume ratios in microscopic droplets, it is necessary to account for surface and bulk solution partitioning when deriving $\sigma$ values from the observations. The compressed film model was used for this purpose, and a full description of the equations and underlying assumptions are available in the supplementary material of Ruehl et al. (2016). The organic compounds at the air-water interface can contribute to $\sigma$ depression, while organic compounds dissolved into the bulk contribute to droplet growth through the Raoult effect. Like the upper-limit surface pressure model above, the compressed film model essentially assumes a phase separation between an organic-rich surface layer and a bulk solution, but with the bulk solution now being a ternary water-inorganic-organic mixture. Also, for the compressed film model the distribution of the organic material between the surface layer and the bulk varies with $\mathrm{RH}$.
This general behavior is similar to the thermodynamic model of liquid-liquid phase separation considered by Ovadnevaite et al. (2017), although the two models differ in terms of their details. The film model is a two-dimensional (2-D) equation of state (EoS) that parameterizes $\sigma$ as a function of molecular area as

$\sigma_{\mathrm{obs}}=\min \left(\sigma_{\mathrm{H}_{2} \mathrm{O}}, \max \left(\sigma_{\mathrm{H}_{2} \mathrm{O}}-\left(A_{0}-A\right) m_{\sigma} \sigma_{\min }\right)\right)$,

where $A_{0}$ is the critical molecular area, $A$ is the molecular area, $m_{\sigma}$ is a term that accounts for the interaction between surfactants at the interface, and $\sigma_{\min }$ is an imposed lower limit for $\sigma$. The $A$ in Eq. (7) may be larger than the $A_{\text {mlc }}$ from Eq. (6) because the assumption of all surfactant molecules at the surface is relaxed. In this model, reductions in $\sigma$ relative to water requires the formation of a full monolayer, which occurs at molecular areas smaller than $A_{0}$. At molecular areas larger than $A_{0}$, the droplet $\sigma$ is assumed to be equal to $72 \mathrm{mN} \mathrm{m}^{-1}$ and the surface phase is said to be in a "gaseous" state where molecules present at the surface do not interact. Strictly speaking, $\pi$ is nonzero in this state, but we assume this increase in $\pi$ is negligible and use $\sigma=72 \mathrm{mN} \mathrm{m}^{-1}$. A 2-D phase change occurs at $A_{0}$ and further addition of surfactant molecules to the interface $\left(A<A_{0}\right)$ causes compression of the surface film. This leads to a sharp decrease in $\sigma$, or increase in $\pi$. The corresponding isotherm for this EoS is given as

$\ln \left(\frac{C_{\text {bulk }}}{C_{0}}\right)=\frac{\left(A_{0}^{2}-A^{2}\right) m_{\sigma} N_{\mathrm{A}}}{2 R T}$,

where $C_{0}$ is the bulk solution concentration at the 2-D phase transition, $C_{\text {bulk }}$ is the bulk solution concentration, $R$ is the gas constant, $N_{\mathrm{A}}$ is Avogadro's number, and $T$ is temperature. The variation of $\sigma$ with $A$ is solved for from the observations by minimizing the chi-square value for $D_{\text {wet }}$ by varying $A_{0}, m_{\sigma}$, and $C_{0}$ with $D_{\text {coat }}, D_{\mathrm{NaCl}}$, and $\mathrm{RH}$ as inputs. The surface tension is constrained to always be larger than some minimum value $\left(\sigma_{\min }\right.$ or $\left.\pi_{\max }\right)$ that is determined as part of the data fitting; this constraint places bounds on the acceptable values of $A_{0}$ and $m_{\sigma}$. The parameters $A_{0}, m_{\sigma}$, and $C_{0}$ are also constrained to be physically realistic, that is with $A_{0}>0$ and $m_{\sigma}$ and $C_{0} \geq 0$. When the system reaches $\sigma_{\min }$ the addition of more molecules or increased compression causes dissolution of surface molecules into the bulk and does not further depress surface tension. An outer iteration uses the Köhler curve to solve for $D_{\text {wet }}$ for a given RH. An inner iteration solves Eq. 8 for the fraction of organic matter at the surface $\left(f_{\text {surf }}\right)$. For each assumed $f_{\text {surf }}$, the inner iteration calculates a value for $C_{\text {bulk }}$ as

$C_{\text {bulk }}=\frac{\left(1-f_{\text {surf }}\right)\left(D_{\text {coat }}^{3}-D_{\text {seed }}^{3}\right)}{D_{\text {wet }}^{3} \bar{V}_{\text {org }}}$,

and $A$ as

$A=\frac{6 \bar{V}_{\text {org }} D_{\text {wet }}^{2}}{f_{\text {surf }}\left(D_{\text {coat }}^{3}-D_{\text {seed }}^{3}\right) N_{\mathrm{A}}}$. 
In Eqs. (9) and (10) the $\bar{V}_{\text {org }}$ is the molecular volume of the organic species. The film model as used here assumes that all organic molecules are either dissolved in the bulk solution or located at the droplet surface. The $\sigma$ is calculated from the $A$ value using Eq. (7). $D_{\text {wet }}$ is then calculated from the water activity (i.e., the Raoult term) using the number of moles of organic species in the bulk droplet (determined from $\varepsilon_{\text {org }}$ and $f_{\text {surf }}$ ) and the number of moles of $\mathrm{NaCl}$ (determined from $D_{\mathrm{NaCl}}$ ). The Kelvin term is calculated based on the derived $\sigma$ value. The parameters $A$ and $C_{\text {bulk }}$ are related through a single unknown, $f_{\text {surf }}$, which is solved for numerically. The parameter $f_{\text {surf }}$ empirically characterizes the fraction of the organic species that reside at the particle surface, with $1-f_{\text {surf }}$ corresponding to the fraction that is dissolved in the bulk. The use of the film model results in a single curve that represents the best-fit $\pi-A$ relationship, rather than the point-bypoint determination that results from the upper-limit method.

Uncertainty in the film model curve was estimated by perturbing the input $\mathrm{RH}$ values by the average precision-based uncertainty in $\mathrm{RH}$, which ranged from 0.008 to $0.01 \%$. The data were then fit to the film model using the perturbed (+ and -) RH values, and the uncertainties were calculated as the difference between the original and perturbed cases. Some of the differences between the film model results and the upper-limit results are due to the upper limit coming from a point-by-point analysis while the film model is a fit across all data points. If the upper-limit values are on the whole equal to film model $\pi$ values, this indicates that dissolution is minimal and that droplet growth enhancement is caused by enhancements in $\pi$ (or reductions in $\sigma$ ). However, if the upper-limit values are systematically lower than the film model $\pi$ values, then droplet growth enhancement is due to both enhancements in $\pi$ and organic compounds dissolving into the bulk.

In addition to the compressed film model, the data were also fit to the Szyszkowski-Langmuir EoS:

$\sigma_{\mathrm{obs}}=\sigma_{\mathrm{H}_{2} \mathrm{O}}-\frac{R T}{A_{0} N_{\mathrm{A}}} \ln \left(1+\frac{C_{\text {bulk }}}{C_{0}}\right)$,

where $C_{0}$ is the bulk concentration at which half of the surface sites are occupied and $A_{0}$ is the maximum surface concentration. The corresponding isotherm is

$$
\frac{A}{A_{0}}=\frac{C_{\text {bulk }} / C_{0}}{1+C_{\text {bulk }} / C_{0}} .
$$

In contrast to the film model, the Szyszkowski EoS does not include an interaction parameter. The Szyszkowski EoS allows for the continuous adsorption and desorption of surfactants from the interface and does not include a 2-D phase transition.
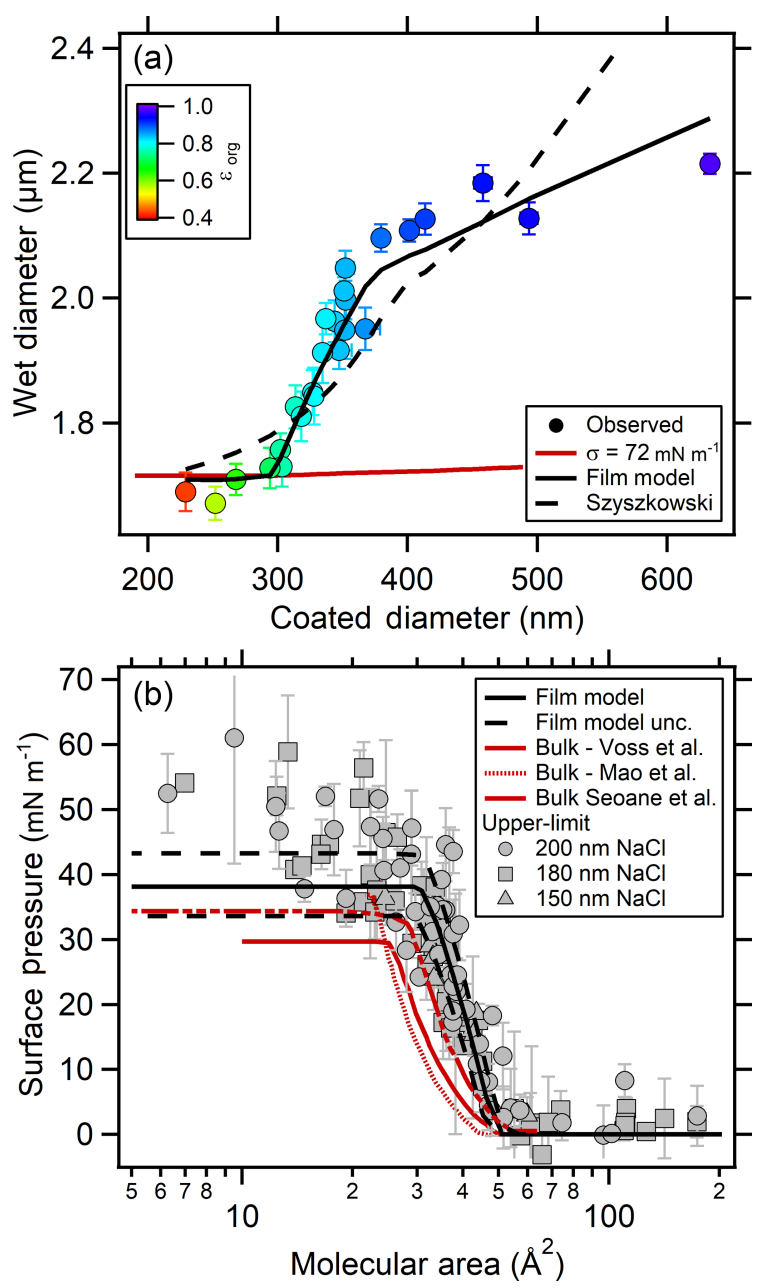

Figure 2. (a) Wet diameter (at $\mathrm{RH}=99.93 \%$ ) vs. dry diameter of $200 \mathrm{~nm} \mathrm{NaCl}$ particles coated with varying amounts of oleic acid. The red line is the calculated droplet size, assuming $\sigma=$ $72 \mathrm{mN} \mathrm{m}^{-1}$, independent of coating amount; and the black and dashed black lines are film model and Szyszkowski model fits to the data, respectively. The error bars correspond to the $95 \%$ confidence interval for mode of the wet diameter distribution. The data points are colored by organic volume fraction $\left(\varepsilon_{\text {org }}\right)$. (b) Upper-limit estimates (grey points) and film model estimates (black lines) for surface pressure as a function of molecular area for various $\mathrm{NaCl}$ seed sizes $($ circles $=200 \mathrm{~nm}$, squares $=180 \mathrm{~nm}$, and triangles $=150 \mathrm{~nm})$ and RH. Error bars on individual points and the film model fit (dashed black lines) are based on the precision in RH. Macroscopic solution measurements (red lines) adapted from Voss et al. (2007), Mao et al. (2013), and Seoane et al. (2000) are included for reference. 
Table 1. Summary of experiments and corresponding compressed film model fit parameters.

\begin{tabular}{|c|c|c|c|c|c|c|c|c|}
\hline Coating & $\begin{array}{r}\text { Range of } \\
\varepsilon_{\text {org }}\end{array}$ & $\begin{array}{r}\mathrm{RH} \\
\text { range }\end{array}$ & $\begin{array}{r}D_{\text {seed }} \\
(\mathrm{nm})\end{array}$ & $\begin{array}{r}\text { Oleic acid } \\
\text { fraction }\end{array}$ & $\begin{array}{r}A_{0} \\
\left(\AA^{2}\right)^{\mathrm{a}}\end{array}$ & $\begin{array}{r}\mathrm{m}_{\sigma} \\
\left(\mathrm{mJ} \mathrm{m}^{-2}\right)\end{array}$ & $\begin{array}{r}\log C_{0} \\
\left(\mathrm{~mol} \mathrm{~mol}^{-1}\right)\end{array}$ & $\begin{array}{r}\pi_{\max } \\
\left(\mathrm{mN} \mathrm{m}^{-1}\right)\end{array}$ \\
\hline Oleic acid $(N=125)$ & $0.42-0.97$ & $99.83-100.03 \%$ & $150,180,200$ & 1 & $48.5 \pm 3.8$ & $2.15 \pm 0.10$ & $-6.10 \pm 0.38$ & $37.5 \pm 4.8$ \\
\hline Myristic acid $(N=43)$ & $0.40-0.98$ & $99.83-99.93 \%$ & 180,200 & 1 & $29.2 \pm 1.2$ & $1.28 \pm 0.20$ & $-7.40 \pm 0.08$ & $\mathrm{c}$ \\
\hline $\begin{array}{l}\text { Oleic acid and palmitic } \\
\text { acid }(N=41)\end{array}$ & $0.58-0.95$ & $99.86-100.00 \%$ & 180,200 & $0.33 \pm 0.08$ & $35.2 \pm 3.3$ & $5.41 \pm 0.88$ & $-5.24 \pm 0.22$ & $43.6 \pm 6.3$ \\
\hline $\begin{array}{l}\text { Oxidized oleic } \\
\operatorname{acid}^{\mathrm{b}}(N=5)\end{array}$ & $0.86-0.88$ & $99.97-99.99 \%$ & 200 & $\%$ & $\mathrm{~b}$ & & & \\
\hline Glutaric acid $^{\mathrm{d}}$ & & & & & 62 & 1.06 & -7 & 42 \\
\hline Pimelic acid ${ }^{\mathrm{d}}$ & & & & & 95 & 0.66 & -6 & 26 \\
\hline
\end{tabular}

\section{Results and discussion}

\subsection{Single surfactant systems}

\subsubsection{Oleic acid coatings}

Variation in the observed wet diameters for $200 \mathrm{~nm}$ sizeselected $\mathrm{NaCl}$ particles coated with oleic acid is shown as a function of the coated particle diameter for one $\mathrm{RH}$ $(\sim 99.94 \%)$ in Fig. 2a. If it is assumed that $\pi$ is constant and equal to that of water (i.e., $\sigma=72 \mathrm{mN} \mathrm{m}^{-1}$ ), the predicted $D_{\text {wet }}$ from Eq. (1) is much lower than the observed $D_{\text {wet }}$, with the difference between the two increasing as the coated diameter (and $\varepsilon_{\text {org }}$ ) increases. This observation indicates that the $\pi$ values in the droplets must be greater than $0 \mathrm{mN} \mathrm{m}^{-1}\left(\sigma_{\mathrm{obs}}<\sigma_{\mathrm{H}_{2} \mathrm{O}}\right)$ for these coated particles or equivalently that $\sigma$ is lower than that of pure water. The difference between the observations and the assumed pure water curve increases with the dry coated particle diameter (and the $\varepsilon_{\text {org }}$ ), but only once the coating reaches a critical value. This threshold behavior, or a minimum required $\varepsilon_{\text {org }}$ to observe an enhancement in the droplet diameter, was previously observed by Ruehl and Wilson (2014) for ammonium sulfate particles coated with oleic acid and other fatty acids.

The wet droplet diameters are used to calculate upper-limit $\pi$ values from Eq. (1) for all $\mathrm{NaCl}$ core sizes, $\mathrm{RH}$, and $\varepsilon_{\text {org }}$ used (see Fig. S4 in the Supplement) and are considered as a function of molecular area (Fig. 2b). Experiments with $\mathrm{NaCl}$ coated with $99 \%$ purity oleic acid and $90 \%$ purity oleic acid were similar, indicating that this change in oleic acid purity did not impact observed $\pi$ values (Fig. S5 in the Supplement). Notably, these upper-limit estimates of $\pi$, when plotted versus $A$, collapse onto a single curve independent of the selected $\mathrm{NaCl}$ seed diameter or measurement $\mathrm{RH}$ (99.85$100.03 \%$ ). This occurs because, when RH is increased (for a given seed diameter), the droplet is larger and the molecular area increases, which then decreases the calculated $\pi$. Similarly, variations in the $\mathrm{NaCl}$ seed diameter (with $\mathrm{RH}$ held constant) lead to variations in $\varepsilon_{\text {org }}$ for a constant coated dry diameter, but this in turn leads to corresponding variations in surface concentrations, molecular areas, and ultimately calculated $\pi$ values. Consequently, the data all collapse onto one curve.

The corresponding compressed film model fit is also shown, both as $D_{\text {wet }}$ versus the dry particle diameter (Fig. 2a) and as $\pi$ versus molecular area (Fig. 2b). Below the threshold $\varepsilon_{\text {org }}$ or above the corresponding $A_{0}$ the film model gives $\pi=0$. In this low-coverage region the surfactant concentration is below monolayer coverage and the molecules are in a gaseous state. Above the threshold $\varepsilon_{\text {org }}$ (or below $A_{0}$ ), a full monolayer forms and $\pi$ begins to increase. In this compression region, as more organic molecules are added (i.e., at larger $\varepsilon_{\text {org }}$ ), compression of the monolayer leads initially to a steep increase in $\pi$ as the molecular area decreases. Eventually $\pi$ reaches a maximum and remains constant at this value. This could be indicative of monolayer collapse, the formation of a three-dimensional phase, and/or dissolution. This region of the $\pi$ isotherm will be referred to as the collapsed region. In contrast, the Szyszkowski EoS does not permit a two-dimensional phase transition and thus cannot reproduce the observed droplet growth behavior (Fig. 2a). Instead, the Szyszkowski EoS yields wet diameters that increase continuously with the coated diameter and that do not exhibit the plateau at high coverage. This indicates that the Szyszkowski $\mathrm{EoS}$ is not appropriate for use with molecules such as oleic acid.

The best fit from the film model for oleic acid on $\mathrm{NaCl}$ gives $A_{0}=48.5 \pm 3.8 \AA^{2}, m_{\sigma}=2.15 \pm 0.1 \mathrm{~mJ} \mathrm{~m}^{-2}$, and $\pi_{\max }=37.5 \pm 4.8 \mathrm{mN} \mathrm{m}^{-1}$ (see Table 1). In the compression region, the film model $\pi$ values are close to upperlimit $\pi$ values. This indicates that the effect of bulk dissolution on the Raoult term is small (bulk solution concentrations $<5 \%$ vol ) and nearly all of the enhanced droplet growth is due to enhancements in $\pi$. In the collapsed region, the film model $\pi$ values are slightly less than the upper-limit estimates, which indicates that bulk dissolution of the organic 
compounds into the bulk solution becomes important following monolayer collapse.

The $\pi-A$ isotherm determined here using the film model for microscopic droplets can be compared to similar measurements for macroscopic systems (see Fig. 2). In the macroscopic measurements, variation in $A$ is induced through physical compression of the surfactant in a Langmuir-Blodgett trough. The $A_{0}$ values for the wet droplets compare well to those in macroscopic systems (Voss et al., 2007; Mao et al., 2013; Seoane et al., 2000). However, the film-model-derived $\pi$ values seem to be higher than the macroscopic system, both in the compression and collapsed region. We hypothesize that this might reflect real physical differences between the droplet and the macroscopic experiments. For one, in typical macroscopic experiments, the molecular areas are changed slowly $\left(0.2\right.$ to $\left.5 \AA^{2} \mathrm{~min}^{-1}\right)$ because they are aimed at measuring under equilibrium conditions. In contrast, in the droplet experiments water uptake and growth occurs rapidly, in just a few seconds. In addition, the droplet growth experiments proceed from a state where the hygroscopic salt core is covered with a purely organic, initially very thick coating (at the highest $\varepsilon_{\text {org }}$ ). This thick coating is stretched out as water uptake by the inorganic core causes the overall particle to increase in size. This is opposite that in typical Langmuir-Blodgett experiments, which start at an expanded state and compress over time. Some macroscopic studies indicate that higher compression rates lead to higher surface pressures during monolayer compression and higher collapsed $\pi$ (Rabinovitch et al., 1960; Jeffers and Daen, 1965; Wüstneck et al., 2005), which is attributed to time-dependent structural changes in the monolayer. Additionally, macroscopic studies measuring time-dependent changes in $\pi$ following rapid expansion indicate that relaxation to the equilibrium state can occur with time constants on the order of $10 \mathrm{~s}$ (Murray and Nelson, 1996) to several minutes (Smith and Berg, 1980), and dynamic surface pressure measurements of atmospheric aerosol extracts indicate that full relaxation can take hundreds of seconds (Noziere et al., 2014).

\subsubsection{Myristic acid coatings}

Upper-limit estimates of $\pi$ and the film model fit to myristicacid-coated $\mathrm{NaCl}$ particles are shown in Fig. 3. Like oleic acid, no enhancements in $\pi$ are observed above a critical threshold at $A_{0}$, i.e., $\pi=0$ when $A>A_{0}$. For myristic acid, $A_{0}=29.2 \pm 1.2 \AA^{2}$ and is smaller than that for oleic acid. This indicates that myristic acid packs more efficiently than oleic acid and that more surfactant molecules are needed at the surface to enhance $\pi$. We suspect this difference arises because oleic acid has a cis double bond, which adopts a bent configuration. This results in less efficient packing at the droplet surface compared to myristic acid, which is a straight-chain alkanoic acid (Kanicky and Shah, 2002). The upper-limit $\pi$ estimates are comparable to the film model.

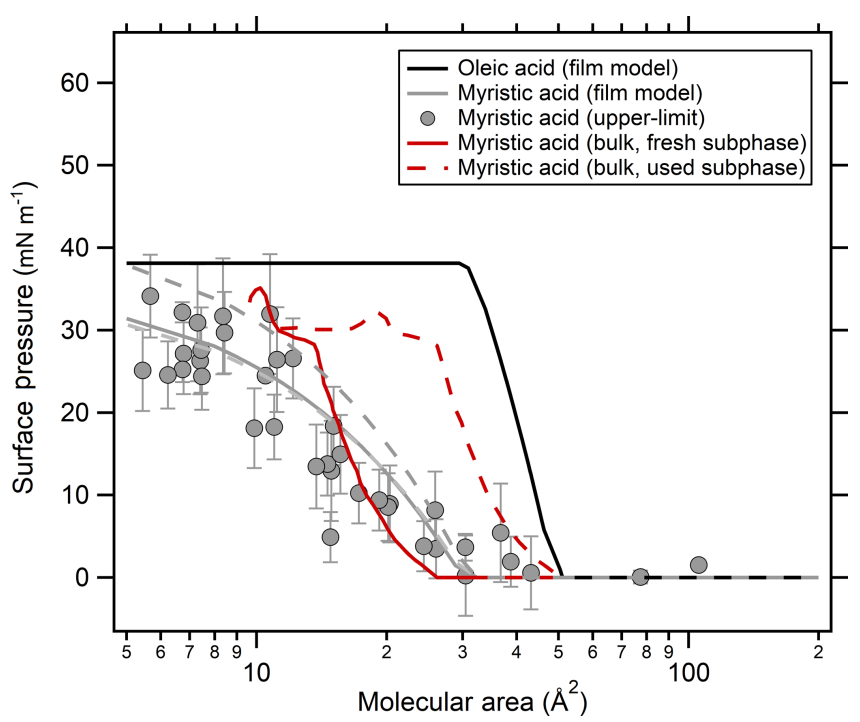

Figure 3. Upper-limit and the film model $\pi$ estimates for $\mathrm{NaCl}$ particles coated with myristic acid as a function of molecular area. Uncertainties in surface pressure are estimated from precision in $\mathrm{RH}$. The black line is the film model estimate for pure oleic acid and the red lines are macroscopic measurements of surface pressure adapted from Albrecht et al. (1999).

This indicates that solubility in the bulk solution played a minimal role.

Takahama and Russell (2011) predict from molecular dynamics studies that the mass accommodation coefficient of water on myristic-acid-coated particles can be suppressed, with the reported range being $0.0-0.04$. Here, there is no evidence that such suppression impacted droplet growth, in contrast to experiments with palmitic acid, discussed below. These findings are consistent with Ruehl and Wilson (2014) for ammonium sulfate particles coated with myristic acid. It may be that myristic acid coatings do reduce the accommodation coefficient from unity, but that the ultimate extent of reduction is insufficient to have a substantial impact on the droplet growth on the timescale of these experiments. In general, the experiments here are reasonably insensitive to variations in the accommodation coefficient when greater than 0.01 (Ruehl and Wilson, 2014).

The myristic acid isotherm for droplets determined here is compared to macroscopic measurements (see Fig. 4). Two different isotherms are shown, both taken from Albrecht et al. (1999). One is for myristic acid compressed on a fresh subphase (water), which corresponds to the first in a series of monolayer compression-expansion cycles. The other is for a used subphase, which corresponds to the eight compression, and where additional surfactant is added prior to each compression. The two isotherms differ substantially. The difference between sequential compression-expansion cycles becomes smaller as the number of cycles increases, and eventually there is little difference between two sequen- 

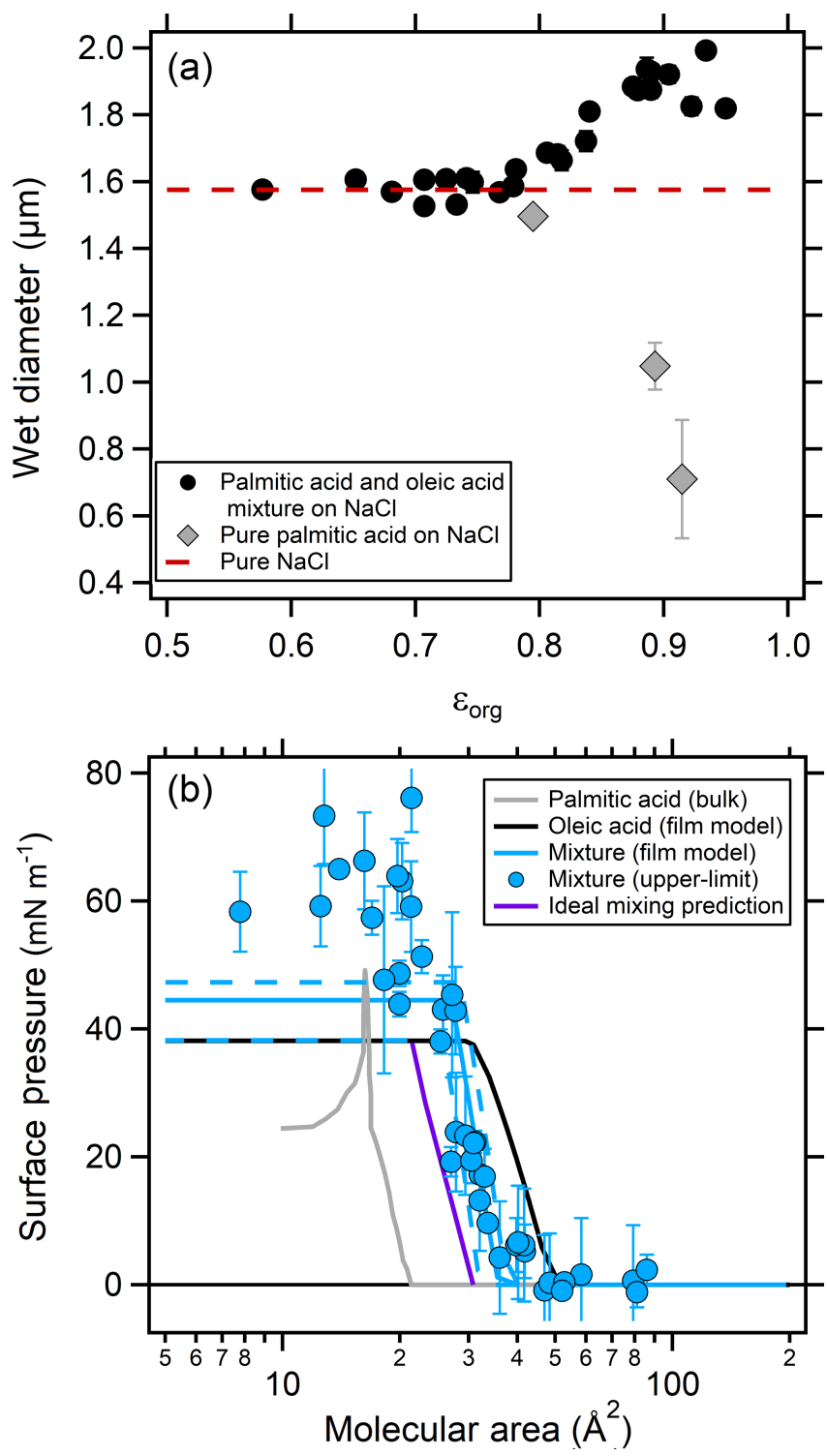

Figure 4. (a) Measured wet diameter at $\mathrm{RH}=99.88 \%$ as a function of organic volume fraction for $200 \mathrm{~nm} \mathrm{NaCl}$ particles coated with pure palmitic acid (diamonds) and a mixture of palmitic acid and oleic acid (triangles). (b) Upper-limit and film model estimates for $\mathrm{NaCl}$ particles coated with a mixture of oleic acid and palmitic acid surface pressure as a function of molecular area. The black line is the oleic acid film model estimate and the grey line corresponds to macroscopic surface pressure measurements from Tang et al. (2010), since surface pressure measurements for $\mathrm{NaCl}$ particles coated with pure palmitic acid were not possible (see text for details). The purple line is the ideal mixing estimate for surface pressure based on the measured molar fractions of oleic acid and palmitic acid.

tial cycles. Albrecht et al. (1999) concluded that myristic acid (as well as other short-chain fatty acids) slowly dissolves into the subphase, with the effects of this process declining over time as the subphase becomes saturated. Thus, whether a fresh or a reused subphase is used has a significant impact on the resulting isotherm for macroscopic systems. This makes a quantitative comparison between the myristic acid isotherm from this study and previous macroscopic studies difficult. The $A_{0}$ for the isotherm observed here on the growing droplets is most similar to the fresh subphase $\left(A_{0} \sim 25 \mathrm{mN} \mathrm{m}^{-1}\right)$ and is substantially smaller than the used subphase $\left(A_{0} \sim 50 \mathrm{mN} \mathrm{m}^{-1}\right)$. Dissolution decreases myristic acid molecules from the interface, which means that lower apparent molecular areas (assuming no dissolution) are required to change $\pi$. However, the dissolution of myristic acid into the bulk is slow, occurring over timescales of tens of minutes (Albrecht et al., 1999). These timescales are much longer than the timescale for droplet growth (seconds). Based on these timescales, dissolution should not play a large role in the experiments presented here, which is consistent with the similarity between the upper-limit $\pi$ and compressed film model. However, observations from Smith and Berg (1980) indicate that larger $\pi$ can lead to greater rates of dissolution (10\% decrease in molecular area over $3 \mathrm{~min}$ at $\pi \sim 22 \mathrm{mN} \mathrm{m}^{-1}$ ). In droplet experiments, the interface is expanding from a highly compressed state (high $\pi$ ). Therefore, it is possible that dissolution was significant for these experiments. However, this conflicts with film model measurements matching the upper limit because it is assumed that solubility is negligible (i.e., $\kappa_{\mathrm{org}}=0$ ) for upper-limit calculations. Nevertheless, the film model is able to reproduce the general $\pi-A$ behavior of this system, even if bulk solution concentration is significant.

\subsubsection{Palmitic acid coatings}

Figure 4a shows droplet diameters as a function of coating thickness for $\mathrm{NaCl}$ particles coated with pure palmitic acid. In the range of temperatures used in these experiments $\left(<25^{\circ} \mathrm{C}\right)$, palmitic acid exists as a waxy solid (Inoue et al., 2004), though it is possible that supercooling can occur (Hearn and Smith, 2005). When palmitic acid is coated on the $\mathrm{NaCl}$ particles with $\varepsilon_{\text {org }} \geq 0.8$, the observed droplet sizes were much lower than what is observed for just the uncoated $\mathrm{NaCl}$ core. As coating thickness (and $\varepsilon_{\text {org }}$ ) increases, the extent of suppression in droplet growth decreases. This indicates that the presence of pure palmitic acid as a coating, especially at thick coatings, inhibits droplet growth. Thus, $\pi$ values could not be determined for these experiments. This behavior is consistent with the low mass accommodation coefficients $(\alpha)$ calculated from Ruehl and Wilson (2014) for ammonium sulfate particles coated with palmitic acid. The dependence of droplet growth suppression on coating thickness is likely due to the slow initial diffusion of water through the palmitic acid coating. Thicker coatings apparently lead to greater inhibition of water transport and slower water diffusion to the $\mathrm{NaCl}$ core, corresponding to an initial period of low $\alpha$. However, as some water infiltrates to the salt core and growth due to water uptake occurs, palmitic acid may 
form islands (Davies et al., 2013; Lovrić et al., 2016). This may lead to the formation of holes that would enhance water transfer, leading to an increase in the effective $\alpha$ over time, which allows the droplets to grow to the observed sizes.

\subsection{Binary surfactant systems}

To understand how mixing of different organic compounds might impact the ability of compounds such as palmitic acid to inhibit water uptake, experiments were carried out for binary oleic-acid-palmitic-acid coating. For these experiments, a 1:1 molar mixture of these surfactants was added to the oven. The CIMS composition measurements indicated that the average oleic acid fraction on the particles was $0.33 \pm 0.08$ (Fig. S6 in the Supplement), which is slightly lower than that of the mixture in the oven. This difference likely results from differences in the vapor pressures of these compounds (Cappa et al., 2008), although they could result from differences in sensitivity of the CIMS to these compounds (Lee et al., 2014). For the mixed palmitic acid and oleic acid coatings on $\mathrm{NaCl}$ seeds, the observed droplet sizes were equal to or larger than that of the pure $\mathrm{NaCl}$ component, with the droplet size increasing as the total coating thickness increased. This indicates that, unlike for pure palmitic acid, the mixed coating does not inhibit water uptake. Thus, there is no evidence of kinetic limitations for this system. Presumably, the mixing of liquid oleic acid (Inoue et al., 2004) with solid and waxy palmitic acid prevented the palmitic acid from packing tightly enough to inhibit initial water uptake.

Since no kinetic limitations were observed for $\mathrm{NaCl}$ particles coated with a palmitic-acid-oleic-acid mixture, it is possible to determine $\pi$ values for these experiments. The $\pi-A$ isotherms from the upper limit and film models for the oleic-acid-palmitic-acid mixture (on $\mathrm{NaCl}$ seeds) are shown in Fig. 4b. These are compared with both the film model curve for oleic acid determined above and observations from palmitic acid solution measurements (Tang et al., 2010). The film model fit yielded $\pi_{\max }=43.6 \pm 6.3 \mathrm{mN} \mathrm{m}^{-1}$ and $A_{0}=35.2 \pm 3.3 \AA^{2}$ (Table 1). The $A_{0}$ is smaller than that for pure oleic-acid-coated particles by $10 \AA^{2}$, indicating that oleic acid packs more efficiently when mixed with palmitic acid. The observed film model isotherm for this system can be compared to the isotherm of an ideal mixture (Adamson and Gast, 1967). The ideal isotherm was calculated from a molar-weighted average of the pure oleic acid isotherm (from the film model fit) and the macroscopic palmitic acid isotherm (Tang et al., 2010). The observed $\pi$ at a given molecular area was higher than the ideal prediction - closer to oleic acid than to palmitic acid. This is consistent with behavior observed in previous work for oleicacid-stearic-acid mixtures in macroscopic solutions (Feher et al., 1977) and indicates some difficulty incorporating the bent double bond in oleic acid into the monolayer. (Stearic acid is a saturated fatty acid that is two carbons longer than palmitic acid and has been observed to suppress water up- take, similarly to palmitic acid; Ruehl and Wilson, 2014.) Other work has found that saturated and unsaturated fatty acids do not mix ideally, but mixed unsaturated-fatty-acidsaturated-fatty-acid films instead form distinct domains enriched in either component (Ocko et al., 2002).

The isotherm for palmitic acid from the measurements made on macroscopic solutions exhibits more complex behavior than is observed for either oleic acid (either for macroscopic solutions or in droplets here) or for the mixture here. For palmitic acid in macroscopic experiments, the $\pi$ increases as $A$ decreases through the compression region until it reaches a sharp maximum. At even greater compression (smaller $A$ ) the $\pi$ then decreases until reaching a plateau. The behavior of palmitic acid stems from the formation of complex 3-D structures following monolayer collapse. If the palmitic acid and oleic acid in the mixture were to form distinct domains there should be two distinct collapse pressures (Ocko et al., 2002; Griffith et al., 2012). Here, the derived upper-limit $\pi$ values for the mixture do not appear to decrease at small $A$ (after the monolayer collapse), instead continuing to rise steadily with decreasing $A$. However, some of this continued increase in $\pi$ likely results from attribution of dissolution of palmitic acid and oleic acid to surface tension in the upper-limit model. In comparison, the $\pi$ values from the film model plateau at small $A$ for the mixture, rather than peak, decline and then plateau as with pure palmitic acid, although it should be noted that the film model is not designed to capture such complex behavior.

Previous modeling (Takahama and Russell, 2011) and experimental (Ruehl and Wilson, 2014; Davies et al., 2013) studies, along with our measurements above, indicate that there can be a kinetic limitation to water evaporation and uptake imposed by films composed of single-component surface-active organic species, in particular long-chain organic species that form solid films, which pack densely and exhibit long-range order. However, $\mathrm{CCN}$ measurements of ambient particles (Raatikainen et al., 2013) suggest that water uptake and droplet growth are not kinetically limited (i.e., $\alpha>0.1)$ for particles sampled at a variety of locations around the world. Here, the observations demonstrate that mixing of one component that did not inhibit water uptake (oleic acid) with another that did (palmitic acid) completely removed the kinetic inhibition. Most likely, the mixing of the two components prevented the formation of a tightly packed film and so water uptake was facile. These observations serve as a potential explanation for why low $\alpha(<0.1)$ water values are not observed for particles in the ambient atmosphere (Raatikainen et al., 2013), since ambient particles are multicomponent mixtures. They also support the suggestion by Davies et al. (2013) that kinetic inhibition to water uptake should rarely be observed in ambient particles, although it is possible that kinetic limitations could become more pronounced at lower temperatures, as decreasing temperature leads to increasing packing density (lower molecular area) (Davies et al., 2013). 
Measurements were also made for a mixture of myristic acid and oleic acid coated on $\mathrm{NaCl}$ particles. For this mixture, the coating composition on the particles was dominated by myristic acid ( $\sim 90 \%$ by mole), even though the mixture composition in the coating apparatus was $1: 1$ by mole. The upper-limit $\pi$ estimates as a function of molecular area are shown in Fig. S7 in the Supplement. At molecular areas $>10 \AA^{2}$, the $\pi$ estimates for the mixture approximately match the pure myristic acid case, but for molecular areas $<10 \AA^{2}$, the surface pressures for the mixed case were slightly larger. The general consistency between the mixed and pure case is consistent with the high myristic acid fraction.

\subsection{Köhler curves and the surface tension at activation}

Above, we showed that the addition of sufficient amounts of fatty acid surfactants to salt particles (here, $\mathrm{NaCl}$ ) can produce substantial $\sigma$ depression (or $\pi$ enhancement) in droplets near the point of activation, that is just above or below $100 \%$ RH. These observations are consistent with other similar observations for both fatty acids and other compounds (Ruehl et al., 2012, 2016; Ruehl and Wilson, 2014). However, an important question is the extent to which this $\sigma$ depression ultimately impacts activation into cloud droplets. Here, this is assessed by measuring $\mathrm{CCN}$ activation curves for $\mathrm{NaCl}$ particles coated with oleic acid, oleic acid mixed with either palmitic acid or myristic acid, and for oleic acid particles oxidized by $\mathrm{O}_{3}$. These activation curves were used to calculate the apparent $\kappa$ values from the measured critical supersaturation $\left(s_{\mathrm{c}}\right)$. The observed $\kappa_{\text {app }}$ values are compared with those predicted assuming volume mixing ( $\kappa_{\text {mix }} ;$ Eq. 4$)$. Any enhancement in $\kappa_{\text {app }}$ values relative to the volume mixing line is attributed to $\sigma$ depression. The observed $\kappa_{\text {app }}$ values are generally consistent with volume mixing rules, although there are some small differences at higher $\varepsilon_{\text {org }}$ (Fig. 5a). Our observations are consistent with Nguyen et al. (2017), who found good agreement between observed and calculated $\kappa_{\text {app }}$ values for sea salt particles coated with various long-chain unsaturated fatty acids, including oleic acid. Values of $\sigma$ at activation reported here were estimated based on the small differences between the $\kappa_{\text {app }}$ and the $\kappa_{\text {mix }}$ by calculating the $\sigma$ required to achieve perfect closure between the observed and calculated $s_{\mathrm{c}}$ when it is assumed that $\kappa=\kappa_{\text {mix }}$. For $\varepsilon_{\text {org }}<0.90$, the calculated values were very close to $72 \mathrm{mN} \mathrm{m}^{-1}$. This indicates that the surfactants have little influence on the CCN activation (i.e., on the $s_{\mathrm{c}}$ ) despite there being substantial depression of $\sigma$ at $\mathrm{RH}$ values slightly lower than the critical value for similar $\varepsilon_{\text {org }}$. Above $\varepsilon_{\text {org }}>0.90$, the average calculated $\sigma$ was $66.4 \pm 2.9 \mathrm{mN} \mathrm{m}^{-1}$, which is slightly less than that for pure water. This indicates that when these surfactants are sufficiently abundant there is a small but non-negligible influence of $\sigma$ depression on activation.

To understand in greater detail the influence of these types of surfactants on CCN activation and to examine the robust-
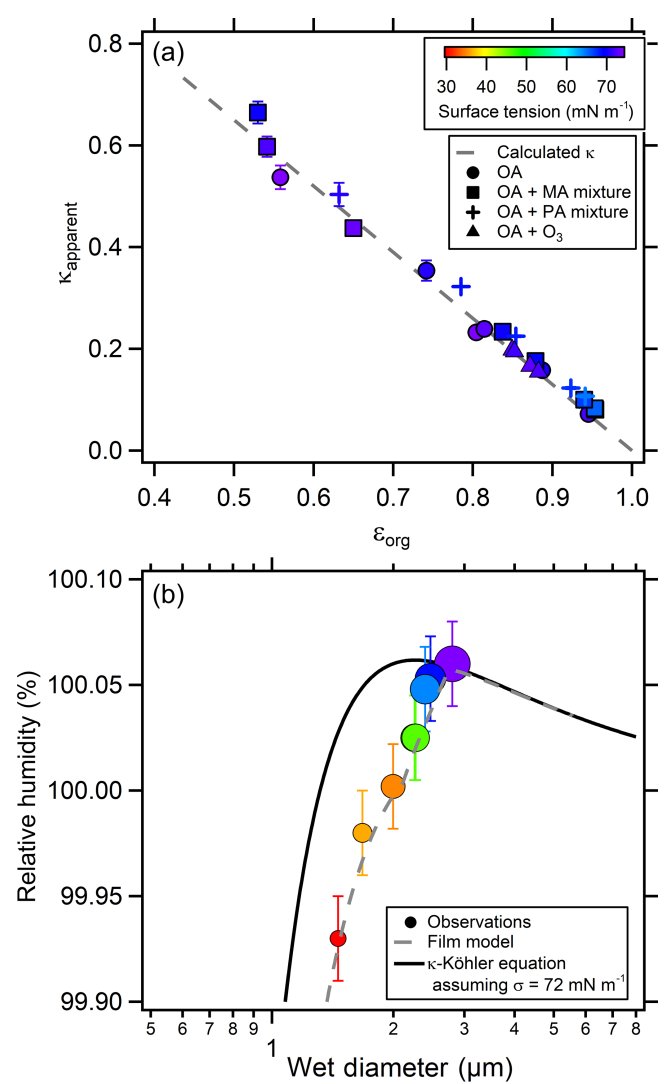

Figure 5. (a) Apparent $\kappa$ values as a function of $\varepsilon_{\text {org }}$ as calculated from the critical supersaturation for $\mathrm{NaCl}$ particles coated with oleic acid (circles), a mixture of myristic acid and oleic acid (squares), a mixture of palmitic acid and oleic acid (crosses), and oxidized oleic acid (triangles). Also shown is the predicted $\kappa$ based on volume mixing rules assuming that $\kappa_{\mathrm{NaCl}}=1.3$ and $\kappa_{\mathrm{org}}=0.001$, with $\sigma=72 \mathrm{mN} \mathrm{m}^{-1}$. Each point is colored by the actual surface tension required to match observations in $\kappa$. (b) Relative humidity as a function of measured wet diameter for $150 \mathrm{~nm}$ (mobility diameter) $\mathrm{NaCl}$ particles coated with a fixed amount of oleic acid $\left(\varepsilon_{\text {org }}=0.95\right)$. Points are colored by upper-limit estimates for surface tension and the size of the points corresponds to the wet diameter. Also shown are values predicted from the compressed film model and $\kappa$-Köhler theory assuming $\sigma=72 \mathrm{mN} \mathrm{m}^{-1}$.

ness of the conclusion that the surfactants have some influence on activation at sufficiently high $\varepsilon_{\text {org }}$, experiments were performed in which the composition of the particle was held constant $\left(\varepsilon_{\text {org }} \sim 0.95\right.$, using oleic acid) while $\mathrm{RH}$ was varied from just below $100 \%$ RH to the point of activation. Figure $5 \mathrm{~b}$ shows the directly observed Köhler curve for these particles, that is the variation in $D_{\text {wet }}$ with RH. The individual points are colored according to the derived $\sigma$ calculated from the upper-limit estimates (Eq. 1). As RH is increased and the particles approach activation, the droplets grow. The growth leads to an increase in both the droplet surface area and the corresponding molecular area, since the number of organic molecules is fixed. This leads to a fairly continuous 
increase in $\sigma$ over the RH range considered. Upon sufficient growth the molecular area increases beyond $A_{0}$ and the reduction in $\sigma$ becomes zero. This underscores the importance of considering surface-area normalized concentrations as opposed to bulk concentrations.

Importantly, the $D_{\text {wet }}$ at which the observed Köhler curve intersects the constant $\kappa$ Köhler curve (calculated assuming $\sigma$ remains constant at $72 \mathrm{mN} \mathrm{m}^{-1}$ ) is past the constant $-\kappa$ maximum (Fig. $5 \mathrm{~b}$ ). Consequently, the observed $s_{\mathrm{c}}(=0.057 \%)$ is slightly lower than that predicted value assuming constant $\sigma\left(s_{\mathrm{c}}=0.062 \%\right)$, which is consistent with the comparison between $\kappa_{\text {app }}$ and $\kappa_{\text {mix }}$ above. This indicates that $\sigma$ depression has some impact on activation, but that the impact is relatively small $(8 \%)$ for the model surfactants used in these experiments. Considered along with the $\mathrm{CCN}$ activation measurements (Fig. 5a), it is also apparent that the surfactants impact the critical supersaturation only at particularly high $\varepsilon_{\text {org }}$. These modest reductions in $\sigma$ are broadly consistent with results found in Schwier et al. (2011) for $\mathrm{NaCl}$ mixed with acidified sodium oleate (where almost all sodium oleate is present as oleic acid) and with Nguyen et al. (2017). Although the ultimate effects on $s_{\mathrm{c}}$ are small for these surfactants, depressions in $\sigma$ change the trajectory of activation through enhancement of droplet sizes, especially at lower RH ( 99.9\%), which is consistent with Ruehl et al. (2016). To have a significant impact on activation, organic compounds must substantially reduce the (maximum) critical supersaturation relative to the pure, uncoated salt.

\subsection{Oxidation experiments}

To understand how oxidation affects $\pi$ (or $\sigma$ ), experiments were conducted in which $\mathrm{NaCl}$ particles coated with oleic acid were oxidized with $\mathrm{O}_{3}$ in a flow tube. Particle size and coating thickness were kept constant, while the residence time in the flow tube was varied to change the extent of oxidation. The composition of the oxidized particles was characterized by a CIMS (Fig. 6a). The average spectra for the most oxidized case and for the pure non-oxidized oleic acid are shown in Fig. S8 in the Supplement. The major oxidation products measured in this study include nonanoic acid, azelaic acid, and 9-oxononanoic acid. As the $\mathrm{O}_{3}$ residence time increased, the absolute abundance and fractional contribution of oleic acid decreased. The most abundant product was 9oxononanoic acid $(\sim 86 \%)$, with minor contributions from azelaic acid $(\sim 7 \%)$ and nonanoic acid $(\sim 7 \%)$. The fractional contribution of products is generally consistent with previous work (Katrib et al., 2004; Hearn and Smith, 2004). Note that some oxidation occurred for the $0 \mathrm{~s}$ case because of the flow tube geometry described above. The diameters of the coated particles decreased relative to the bypass channel upon reaction with $\mathrm{O}_{3}$, likely due to the formation and subsequent evaporation of nonanal. The volume of the particles was reduced by $8 \%$ for lightly oxidized particles and $18 \%$
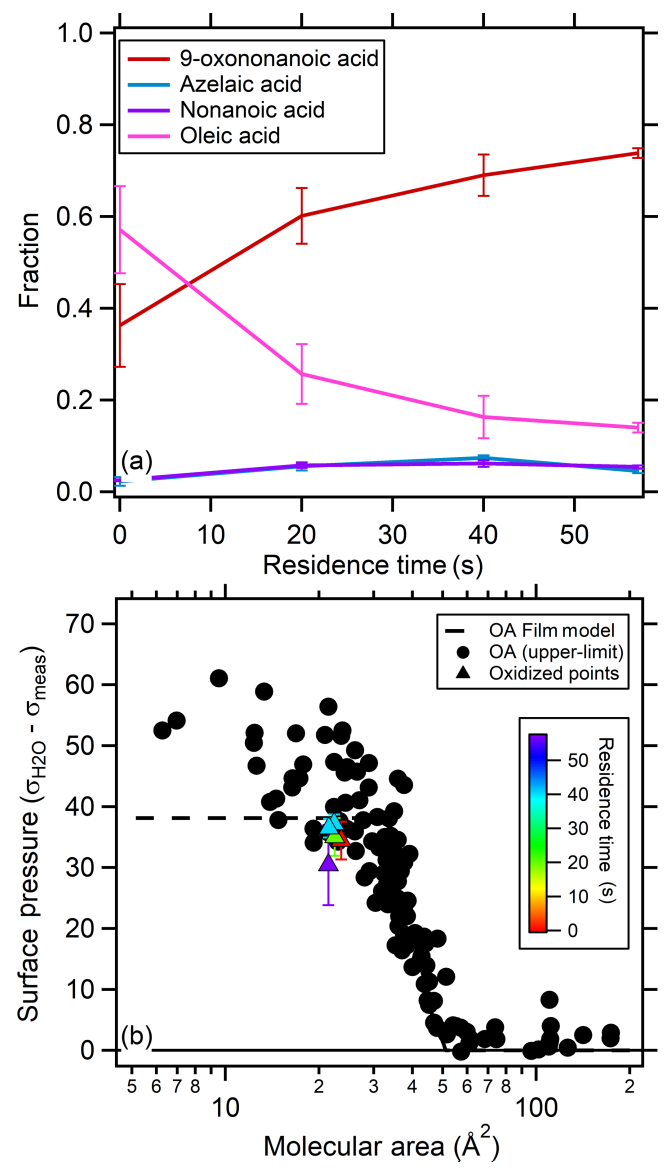

Figure 6. (a) Fractional contribution of oleic acid and oxidation products as a function of residence time. (b) Surface pressures as a function of molecular area for oxidized oleic-acid-coated $\mathrm{NaCl}$ particles colored by residence time (triangles). Upper-limit surface pressure estimates (black circles) and film model estimate (dashed black line) for unoxidized oleic-acid-coated $\mathrm{NaCl}$ experiments are provided for comparison.

for highly oxidized particles. The $\varepsilon_{\text {org }}$ for the oxidized particles ranged from 0.86 to 0.88 , after reaction.

The CCN-derived $\kappa_{\text {app }}$ values were used to assess changes in solubility of the coating material, assuming that the $\sigma$ of oleic-acid-coated $\mathrm{NaCl}$ is close to that of water at activation, a reasonable assumption given the results shown above. A difference between the observed $\kappa_{\text {app }}$ values and the calculated $\kappa_{\text {mix }}$ could indicate an increase in the solubility of the organic component after oxidation. Shown in Fig. 5a are the measured $\kappa_{\text {app }}$ values for each oxidation condition at the measurement $\varepsilon_{\text {org }}$ and the theoretical line for the volume mixing assumption (assuming $\sigma=72 \mathrm{mN} \mathrm{m}^{-1}$ ). The measured $\kappa_{\text {app }}$ values for the oxidized particles are very similar to both the volume mixing line and to the unoxidized oleicacid-coated $\mathrm{NaCl}$ particles. This indicates that changes in solubility were minimal. This minimal change in solubility is supported by the low $\kappa$ values $(\sim<0.003)$ for 9 -oxononanoic acid and nonanoic acid predicted from a functional group 
model (Petters et al., 2016). Azelaic acid has a higher observed $\kappa_{\text {app }}$ value of 0.02 (Kuwata et al., 2013), but, since this product is only a minor component of the coating material, it does not have a strong impact on the overall $\kappa$.

Given that the observations indicate no substantial change in solubility, upper-limit $\pi$ values for oxidized particles have been determined, as measured before activation at $\mathrm{RH}$ $\sim 100 \%$. The $\pi$ values for oxidized particles at a given $A$ are compared to the $\pi-A$ isotherm measured for unoxidized oleic acid particles (Fig. 6b). Molecular areas were calculated using molar-weighted fractions of oleic acid and the oxidation products. After oxidation, the $\pi$ values of these particles are still well above that of pure water. There is some indication that the $\pi$ values for oxidized particles are lower than that for unoxidized particles at the same molecular area, although the difference is generally small. These observations are reasonably consistent with previous findings in Schwier et al. (2011) for particles composed of acidified sodium oleate and $\mathrm{NaCl}$ reacted with $\mathrm{O}_{3}$ at somewhat higher exposures than here (exposure $\sim 8.8 \times 10^{14}$ to $4.4 \times 10^{15}$ molecules $\mathrm{cm}^{-3} \mathrm{~s}$ ). However, unlike the observations presented here, the $\sigma$ values for their experiments were estimated at activation based on the observed $s_{\mathrm{c}}$ and so the overall influence of reductions in $\sigma$ should be much smaller.

\section{Developing broader understanding via the film model}

\subsection{Sensitivity to film model parameters}

To go beyond the specific chemical systems experimentally investigated here, the film model can be used. The film model allows for theoretical exploration of the relationship between the properties of surface-active organic molecules (characterized by $A_{0}, m_{\sigma}, C_{0}$ and $\sigma_{\min }$, and also the molecular volume or $v_{\text {org }}$ ) and $s_{\mathrm{c}}$ and $\kappa_{\text {app }}$. This serves to establish under what conditions the addition of organic material should lead to a reduction in the $s_{\mathrm{c}}$ (and increase in $\kappa_{\text {app }}$ ) and more efficient $\mathrm{CCN}$ relative to that expected from volume mixing rules. As a starting point, theoretical Köhler curves have been calculated for three specific sets of film model parameters: (i) those determined here for oleic acid, and those determined by Ruehl et al. (2016) for (ii) glutaric and (iii) pimelic acid (Table 1). Glutaric acid and pimelic acid were selected because, unlike oleic acid, they were observed by Ruehl et al. (2016) to have a substantial impact on $s_{\mathrm{c}}$ and $\kappa_{\text {app }}$ through reductions in $\sigma$. Glutaric acid is a five-carbon and pimelic acid a seven-carbon straight-chain dicarboxylic acid. The calculations use $80 \mathrm{~nm} \mathrm{NaCl}$ seed particles coated to $\varepsilon_{\text {org }}=0.80$, which corresponds to a coated particle diameter of $136.8 \mathrm{~nm}$ (Fig. 7a). The selected $\varepsilon_{\text {org }}$ value is similar to that observed for SSA with $D_{\mathrm{p}}<200 \mathrm{~nm}$ generated from laboratory breaking waves in seawater during a microcosm (Deane et al., 2018) and to that observed for ambient marine particles in high chlorophyll $a$ environments (O'Dowd et al.,
2004). The film model results are compared to the Köhler curve calculated assuming the organic component was insoluble and that $\sigma=72 \mathrm{mN} \mathrm{m}^{-1}$, referred to as the constant $\sigma$ or no $\sigma$ reduction case. All $\kappa_{\text {app }}$ values are calculated from the model-predicted $s_{\mathrm{c}}$ values, which account for $\sigma$ reduction, assuming that there is no $\sigma$ reduction.

For the constant $\sigma$ case the calculated $s_{\mathrm{c}}=0.142 \%$, corresponding to $\kappa_{\text {app }}=0.27$, for these conditions. For oleic acid, the calculated critical supersaturation and $\kappa_{\text {app }}$ were unchanged from the constant $\sigma$ case (Fig. 7a). This is because the calculated $\sigma$ in the film model reaches $72 \mathrm{mN} \mathrm{m}^{-1}$ at a $D_{\text {wet }}$ that is substantially smaller than the critical diameter for the constant $\sigma$ case (Fig. 7b). In contrast, the $s_{\mathrm{c}}$ for glutaric and pimelic acid coated particles are reduced slightly and the $\kappa_{\text {app }}$ increased slightly to $s_{\mathrm{c}}=0.137\left(\kappa_{\text {app }}\right.$ $\left(\kappa_{\text {app }}=0.29\right)$ and $0.133\left(\kappa_{\text {app }}=0.31\right)$, respectively. This is because the reduction in $\sigma$ persists to beyond the constant $\sigma$ case activation point for these cases. The particles ultimately activate at the point where $\sigma$ reaches $72 \mathrm{mN} \mathrm{m}^{-1}$, the constant $\sigma$ value, as was noted by Ruehl et al. (2016). The difference between oleic acid and the two dicarboxylic acids results in part from oleic acid having a larger $v_{\text {org }}$. Consequently, the molecular area for oleic acid (at $\varepsilon_{\text {org }}=0.8$ ) substantially exceeds $A_{0}$ prior to the constant $\sigma$ activation point and there is no impact of the reduction in $\sigma$ observed at slightly lower RH on the actual $s_{\mathrm{c}}$ or $\kappa_{\text {app}}$. This is not the case for the two diacids, and thus surface tension depression impacts $s_{\mathrm{c}}$. For comparison, at the activation diameter of the constant $\sigma$ case $(0.98 \mu \mathrm{m})$ the $A$ for oleic acid is $\sim 150 \AA^{2}$ but only $95 \AA^{2}$ for glutaric acid and $62 \AA^{2}$ for pimelic acid (see Fig. 7c).

Given the above, the general sensitivity of $\kappa_{\text {app }}$ to the surfactant properties (and their influence on $\sigma$ depression) has been more systematically assessed, again using $80 \mathrm{~nm} \mathrm{NaCl}$ seed particles. The predicted $\kappa_{\text {app }}$ values from the film model were found to be most sensitive to variations in the $v_{\text {org }}$ and the $A_{0}$ of the organic species (Fig. 8). The predicted $\kappa_{\text {app }}$ values were not sensitive to variations in $m_{\sigma}$ values above $0.1 \mathrm{~mJ} \mathrm{~m}^{-2}$ and variations in $C_{0}$ had limited impact for $A_{0}<100 \AA^{2}$. Additionally, the predicted $\kappa_{\text {app }}$ values were not sensitive to $\sigma_{\min }$ for values below $65 \mathrm{mN} \mathrm{m}^{-1}$. Thus, we focus on $v_{\text {org }}$ and $A_{0}$.

The dependence of $\kappa_{\text {app }}$ on the organic species $v_{\text {org }}$ and $A_{0}$ is examined for two cases: $\varepsilon_{\text {org }}=0.8$ (Fig. 8a) and $\varepsilon_{\text {org }}=0.9$ (Fig. 8b). (For these calculations, $m_{\sigma}=1.0 \mathrm{~mJ} \mathrm{~m}^{-2}, C_{0}=$ $1 \times 10^{-6} \mathrm{~mol} \mathrm{~mol}^{-1}$, and $\sigma_{\min }=40 \mathrm{mN} \mathrm{m}^{-1}$.) For a given $\varepsilon_{\text {org }}$, species with smaller $\nu_{\text {org }}$ have smaller molecular areas (higher surface-area-normalized concentrations) at a given $D_{\text {wet }}$. Thus, the extent of $\sigma$ depression is greater for smaller $v_{\text {org. }}$. This is consistent with the observations in Ruehl and Wilson (2014). We find that the sensitivity of $\kappa_{\text {app }}$ to a change in $v_{\text {org }}$ increases as $v_{\text {org }}$ becomes small. Likewise, species with larger $A_{0}$ will require less surfactant at the surface to reduce $\sigma$ and impact activation. The calculated $\kappa_{\text {app }}$ values are approximately constant over a wide range of $A_{0}$ and 

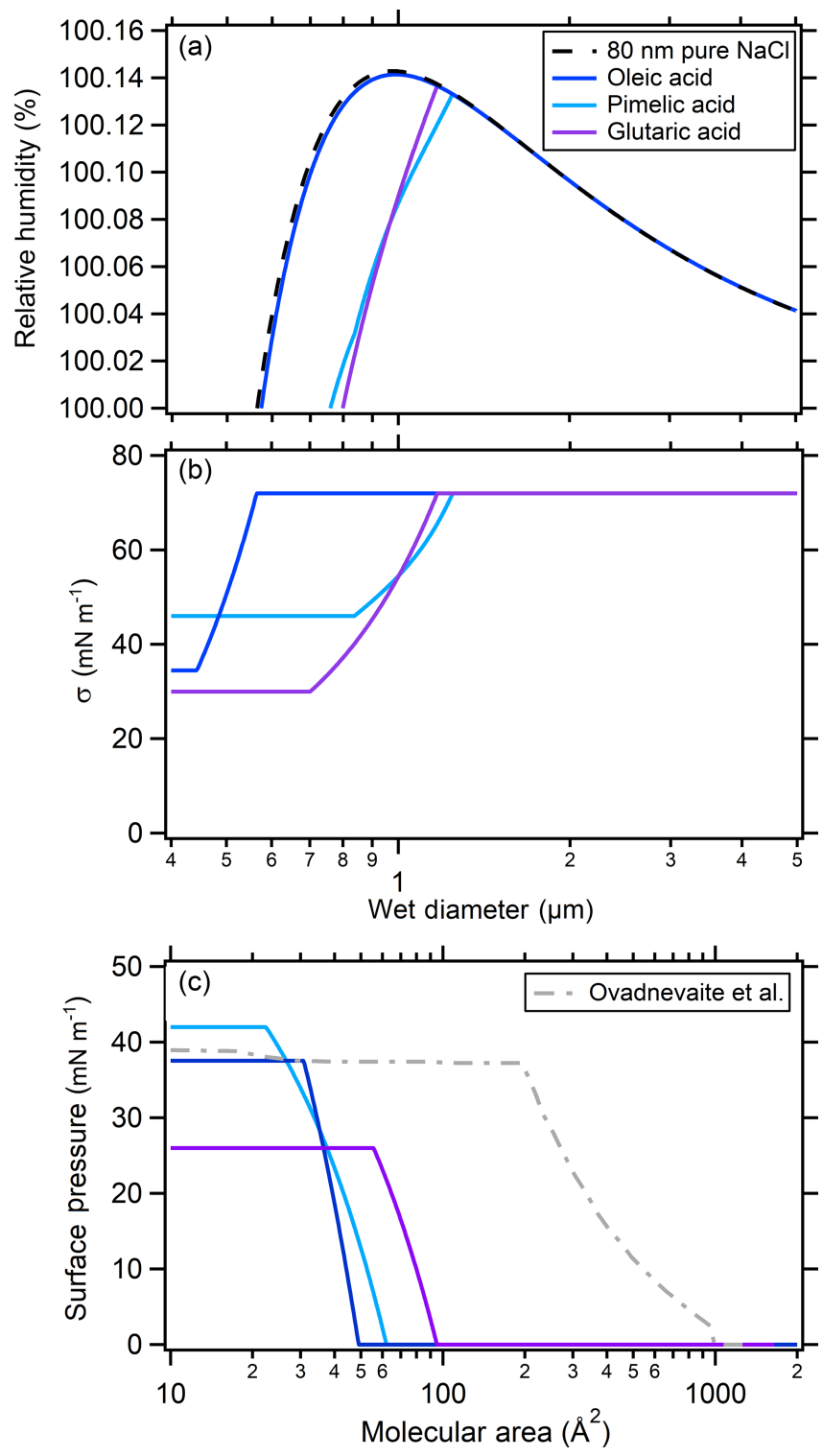

Figure 7. Film-model-derived (a) relative humidity and (b) surface tension $(\sigma)$ as a function of wet diameter for uncoated $80 \mathrm{~nm} \mathrm{NaCl}$ particles (dashed black line) or $80 \mathrm{~nm} \mathrm{NaCl}$ particles coated with oleic acid (dark blue line), pimelic acid (light blue line), and glutaric acid (purple line) until $\varepsilon_{\text {org }}=0.80$. Film model parameters for oleic acid are from this study, while the parameters for glutaric acid and pimelic acid were taken from Ruehl et al. (2016). (c) Surface pressure $(\pi)$ as a function of molecular area for the coated-particle model systems in (a) and (b). Also shown is the $\pi$ curve derived from Ovadnevaite et al. (2017) based on the reported wet diameter and $\sigma$, assuming $\rho_{\text {org }}=1.6 \mathrm{~g} \mathrm{~cm}^{-3}$ and a molecular weight $=332 \mathrm{~g} \mathrm{~mol}^{-1}$.

$v_{\text {org }}$, in particular when $A_{0}$ is small and $v_{\text {org }}$ is large, with $\kappa_{\text {app }} \sim 0.3$ when $\varepsilon_{\text {org }}=0.8$ and $\kappa_{\text {app }} \sim 0.17$ when $\varepsilon_{\text {org }}=0.9$ (Fig. 8a). These values are very similar to those predicted from volume mixing rules assuming $\sigma=72 \mathrm{mN} \mathrm{m}^{-1}$. However, when $A_{0}$ is instead relatively large and/or $v_{\text {org }}$ is rel-

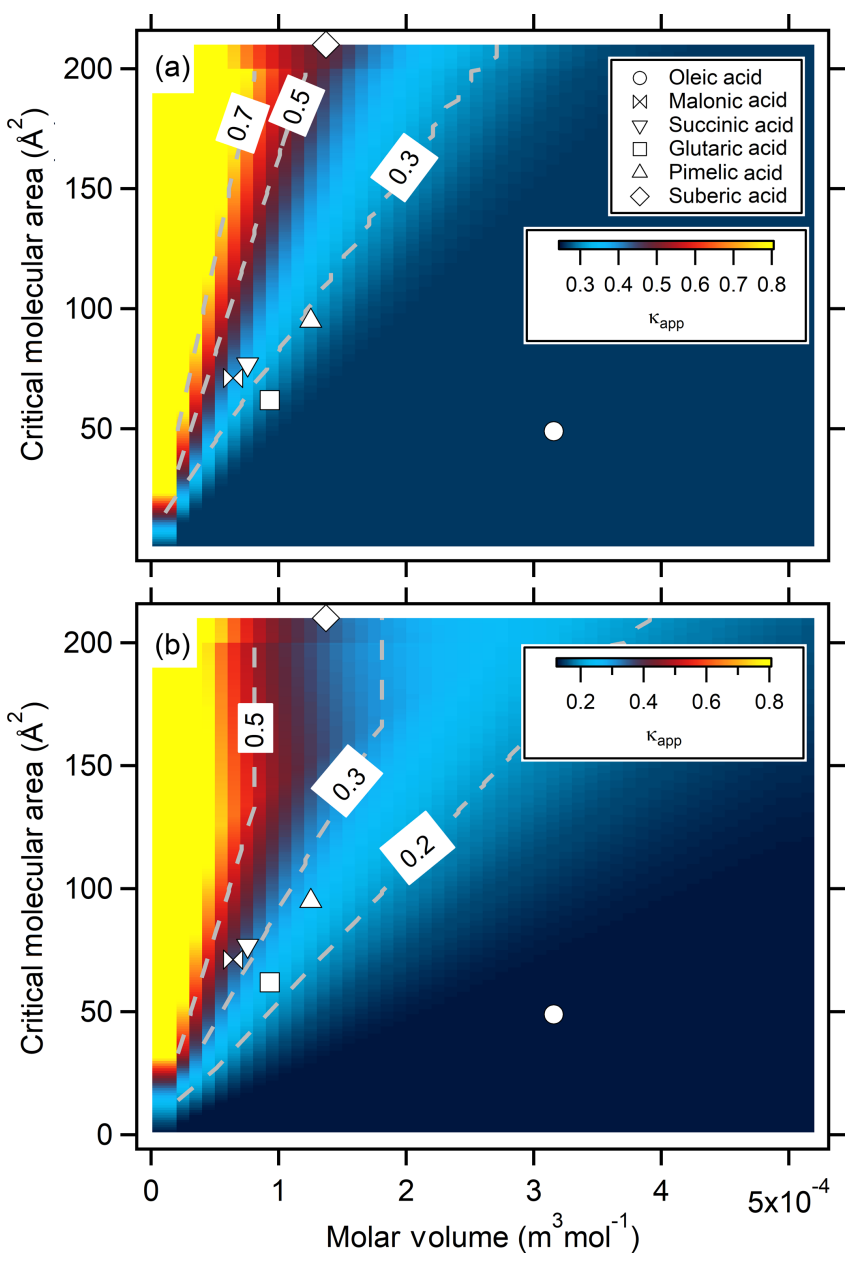

Figure 8. Apparent $\kappa$ values calculated as function of critical molecular area $\left(\AA^{2}\right)$ and molar volume $\left(\mathrm{m}^{3} \mathrm{~mol}^{-1}\right)$ from the film model, with the color corresponding to $\kappa_{\text {app }}$. Results are shown for $80 \mathrm{~nm} \mathrm{NaCl}$ particles coated to organic fractions $\left(\varepsilon_{\mathrm{org}}\right)$ of either (a) 0.80 or (b) 0.90 . Also shown are the observed film model fit parameters for oleic acid (circle) from this study. Parameters for glutaric acid (square), succinic acid (upside down triangle), glutaric acid (square), pimelic acid (triangle), and suberic acid (diamond) are from Ruehl et al. (2016). The color scales for panels A and B range from 0.25 to 0.8 and 0.13 to 0.8 , respectively, with the color scale saturating at 0.8 .

atively small the $\kappa_{\text {app }}$ can be very large, with substantial changes in $\kappa_{\text {app }}$ predicted for relatively modest changes in $v_{\text {org }}$. The exact transition from the nearly constant $\kappa_{\text {app }}$ to the $A_{0}$ and $\varpi_{\text {org }}$-sensitive $k_{\text {app }}$ depends on $\varepsilon_{\text {org }}$. In general, for larger $\varepsilon_{\text {org }}$ the $\mathrm{k}_{\text {app }}$ becomes sensitive to variations in $v_{\text {org }}$ and $A_{0}$ at larger absolute $v_{\text {org }}$. These calculations demonstrate that it is, at least in theory, possible to observe large $\kappa_{\text {app }}$ values for mixed inorganic-organic particles even when the organic fraction is large. However, substantial increases in $\kappa_{\text {app }}$ are only obtained for a particular range of organic properties, within the film model framework. 


\subsection{Linking to sea spray and secondary marine aerosol}

The chemical systems considered in this study - long-chain fatty acids coated on $\mathrm{NaCl}$ - were considered in part because even-numbered fatty acids have been identified as substantial components in submicron sea spray aerosol particles (Cochran et al., 2016; Schmitt-Kopplin et al., 2012; Mochida et al., 2007). Our measurements demonstrate that the fatty acids can have a substantial impact on $\sigma$ near activation, when present at sufficient abundance, but that reductions in $\sigma$ ultimately have limited impact on activation (i.e., on $s_{\mathrm{c}}$ ). A lowering of $s_{\mathrm{c}}$ due to reductions in $\sigma$ has been used (or hypothesized) to explain the often large $\mathrm{CCN}$ activation efficiency for particles observed in the marine environment or in microcosm experiments, in particular nascent SSA particles. For example, Ovadnevaite et al. (2011) observed high CCN activity concurrent with low water uptake at sub-saturated RH for ambient SSA particles sampled during a field study. In general, at RH values well below $100 \%$ the Raoult, or solubility, effect primarily controls water uptake, with limited influence of $\sigma$ (and thus limited sensitivity to variations in $\sigma$ ). Thus, the low water uptake under sub-saturated conditions indicates the particles have limited salt content, and the difference between the $\mathrm{CCN}$ and sub-saturated measurements implicates $\sigma$ as an important factor. As another example, Collins et al. (2016) observed persistently high CCN activation efficiency $\left(\kappa_{\text {app }}>0.7\right)$ for microcosm studies of nascent SSA with $D_{\mathrm{p}}<200 \mathrm{~nm}$ regardless of the biological activity within the seawater used. This was even though the SSA with $D_{\mathrm{p}}<200 \mathrm{~nm}$ particles was likely highly enriched in organic matter during these mesocosms (Deane et al., 2018), and thus much smaller $\kappa_{\text {app }}$ would be expected. This again implies an important role for $\sigma$ in affecting the $\mathrm{CCN}$ activity. Rasmussen et al. (2017) report a negligible difference in $\mathrm{CCN}$ activity between artificial seawater, real seawater, and seawater spiked (at $1-5 \%$ by volume) with sea surface microlayer samples. However, as with Collins et al. (2016), no composition measurements were made.

If $\sigma$ depression is responsible for the observed high $\mathrm{CCN}$ activity of SSA then the average properties of the marine surfactants must differ substantially from the fatty acids systems tested here, given the distinct lack of impact of the fatty acids on $s_{\mathrm{c}}$ observed here and by Nguyen et al. (2017). Our theoretical analysis above using the film model suggests that the complex mixture of marine organic compounds (which includes fatty acids) with salts must interact to have an effective $A_{0}>100 \AA^{2}$ and overall relatively small $v_{\text {org }}$ values.

In Sect. 4.1, the dependence of $\kappa_{\text {app }}$ on $A_{0}$ and $v_{\text {org }}$ was examined for particles with constant $\varepsilon_{\text {org }}$. Here, drawing on the Collins et al. (2016) observations, calculations of $\kappa_{\text {app }}$ have been performed as a function of $\varepsilon_{\text {org }}$ for select pairs of $A_{0}$ and $v_{\text {org }}$. This provides insight into how variation in the relative abundances of salts and organics in (theoretical) SSA particles could impact $\kappa_{\text {app }}$. Three pairs of $A_{0}$ and $v_{\text {org }}$ values were chosen to produce $\kappa_{\text {app }}$ values at $\varepsilon_{\text {org }}=0.8$ of $\kappa_{\text {app }}=0.35,0.50$, and 0.70 for an $80 \mathrm{~nm}$ $\mathrm{NaCl}$ seed particle, which can be compared to $\kappa_{\text {app }}=0.27$ if $\sigma=72 \mathrm{mN} \mathrm{m}^{-1}$. There is more than one $\left(A_{0}, v_{\text {org }}\right)$ pair that yields the same $\kappa_{\text {app }}$ (Fig. 8a). Thus, the specific pair chosen here were selected to test the sensitivity of $\kappa_{\text {app }}$ to each parameter, and the three pairs considered were (i) $A_{0}=150 \AA^{2}, \quad v_{\text {org }}=0.6 \times 10^{-4} \mathrm{~m}^{3} \mathrm{~mol}^{-1}$; (ii) $A_{0}=$ $100 \AA^{2}, v_{\text {org }}=0.6 \times 10^{-4} \mathrm{~m}^{3} \mathrm{~mol}^{-1}$; and (iii) $A_{0}=100 \AA^{2}$, $v_{\text {org }}=10 \times 10^{-5} \mathrm{~m}^{3} \mathrm{~mol}^{-1}$. For the parameter combinations tested, the $\kappa_{\text {app }}$ decreases monotonically with $\varepsilon_{\text {org }}$ when $\varepsilon_{\text {org }}<0.5$, following the volume mixing line assuming constant $\sigma=72 \mathrm{mN} \mathrm{m}^{-1}$ (Fig. 9). The decrease in $\kappa_{\text {app }}$ with $\varepsilon_{\text {org }}$ in this range results from the increased fraction of insoluble organic material, but with no influence on the $\sigma$ because the organic material is not sufficiently abundant. However, at $\varepsilon_{\text {org }}>0.5$, the organic material is sufficiently abundant to reduce $\sigma$ and this buffers the decline in $\kappa_{\text {app }}$ that results from addition of insoluble material. That is, at $\varepsilon_{\text {org }}>0.5$ the calculated $\kappa_{\text {app }}$ values are relatively insensitive to variations in $\varepsilon_{\text {org }}$ and are larger than that obtained assuming $\sigma=72 \mathrm{mN} \mathrm{m}^{-1}$. Consistent with the above analysis (Fig. 8a), for a given $A_{0}$ a decrease in $v_{\text {org }}$ leads to an increase in $\kappa_{\text {app }}$ - here from $0.35\left(v_{\text {org }}=1 \times 10^{-4} \mathrm{~m}^{3} \mathrm{~mol}^{-1}\right)$ to $0.50\left(v_{\text {org }}=6 \times 10^{-5} \mathrm{~m}^{3} \mathrm{~mol}^{-1}\right)$ when $A_{0}=100 \AA^{2}$ and $\varepsilon_{\text {org }}=0.8$. Correspondingly, at a given $v_{\text {org }}$ an increase in $A_{0}$ leads to an increase in $\kappa_{\text {app }}$ - here from $0.50\left(A_{0}=100 \AA^{2}\right)$ to $0.67\left(A_{0}=150 \AA^{2}\right)$ when $v_{\text {org }}=6 \times 10^{-5} \mathrm{~m}^{3} \mathrm{~mol}^{-1}$ and $\varepsilon_{\text {org }}=0.8$. The exact dependence of $\kappa_{\text {app }}$ on $\varepsilon_{\text {org }}$ depends on the assumed film model parameters (Fig. 9). In certain cases, the $\kappa_{\text {app }}$ can even increase with increasing $\varepsilon_{\text {org }}$. Regardless of the exact behavior, this exercise demonstrates that $\sigma$ depression by mostly insoluble species has the potential to buffer observations of $\kappa_{\text {app }}$ against changes in composition. Relevant to nascent SSA particles, in particular, we find it is theoretically possible for this buffering effect to maintain $\kappa_{\text {app }}>0.7$ even at high $\varepsilon_{\text {org }}$. It may be that such buffering effects explain the observations of Collins et al. (2016), who observed variability in the $\kappa_{\text {app }}$ values for nascent SSA particles over the range $\kappa_{\text {app }}=0.7-1.3$ for a wide range of chlorophyll $a$ concentrations, but did not observe $\kappa_{\text {app }}<0.7$.

Beyond SSA, recent observations of the CCN activity of very small, ambient secondary marine aerosol (SMA) particles have also been interpreted as indicating that $\sigma$ depression has a substantial impact on $s_{\mathrm{c}}$ (Ovadnevaite et al., 2017). Ovadnevaite et al. (2017) report the relationship between $\sigma$ and $D_{\text {wet }}$ obtained from thermodynamic calculations of the droplet-phase behavior (in particular, liquid-liquid phase separation) and an assumption that $\sigma$ can be calculated as the surface-area-weighted mean of the composition-dependent $\sigma$ for each of the two liquid phases. Here, we have translated the reported $\sigma-D_{\text {wet }}$ relationship to $\pi$ versus $A$ (see Fig. 7c). It was assumed here that the organic mass fraction $=0.55$ (as reported) and that $\rho_{\text {org }}=1.6 \mathrm{~g} \mathrm{~cm}^{-3}$ and $M W_{\text {org }}=332 \mathrm{~g} \mathrm{~mol}^{-1}$; these are the estimated density and molecular weight of the dimer species used as surrogate com- 


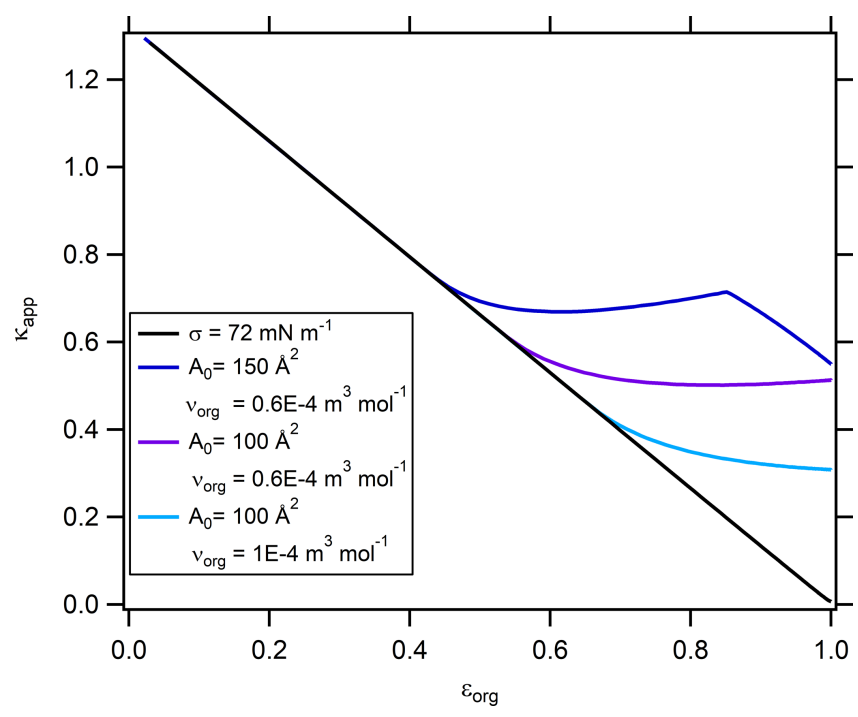

Figure 9. Apparent $\kappa\left(\kappa_{\text {app }}\right)$ as a function of $\varepsilon_{\text {org }}$ for mixed $\mathrm{NaCl}-$ organic particles having a constant total diameter $(136.8 \mathrm{~nm})$, calculated using the film model. The black line is the constant $\sigma$ case, the dark blue line was calculated using $A_{0}=150 \AA^{2}$ and $v_{\text {org }}=0.6 \times 10^{-4}$, the purple line is calculated using $A_{0}=100 \AA^{2}$ and $v_{\text {org }}=0.6 \times 10^{-4}$, and the light blue line is calculated using $A_{0}=100 \AA^{2}$ and $v_{\text {org }}=1 \times 10^{-4}$.

pounds used by Ovadnevaite et al. (2017) and correspond to a $v_{\text {org }}$ of $2.1 \times 10^{-4} \mathrm{~m}^{3}$ mol. The inferred $A_{0}$ is $1000 \AA^{2}$. This is much larger than the compounds considered here and might generally be considered as very large. Consistent with our above general analysis, it is evident that large $A_{0}$ values, in addition to sufficiently low $v_{\text {org }}$, are necessary to significantly reduce critical supersaturations. The reason for the particularly large derived $A_{0}$ (based on their reported $\sigma-D_{\text {wet }}$ relationship) is not totally clear but is likely related to their assumption of the minimum coating amount (reported as a minimum thickness) necessary to impact $\sigma$. If the minimum thickness for a given compound is low, the buffering effect described above would be significant, even at lower $\varepsilon_{\text {org }}$ values, because a much lower concentration of surfactants at the surface (higher molecular area) would be required to reduce $\sigma$. Yakobi-Hancock et al. (2014) measured $\kappa_{\text {app }}$ values for ambient 50 and $100 \mathrm{~nm}$ particles on the west coast of Vancouver Island, sampling often marine-influenced air. They observed substantial variability in the $\kappa_{\text {app }}$ values, partly attributable to variations in the sulfate-to-organic ratio but, we speculate, with at least some of the remaining scatter potentially resulting from variability in $\sigma$ depression at activation, depending on the exact chemical nature of the organic material.

\section{Conclusion}

In this study, surface tension values were estimated for droplets at $\mathrm{RH}$ near activation that were grown from $\mathrm{NaCl}$ particles coated with the fatty acids oleic acid, myristic acid or palmitic acid, or a palmitic-acid-oleic-acid mixture. The retrieved $\sigma$ depended explicitly on the relative amount of organic coating, the exact $\mathrm{RH}$, and the identity of the fatty acid. For particles with $\varepsilon_{\text {org }}>0.80$, the observed $\sigma$ values were reduced significantly compared to pure water. Observed variability in the relationships between $\sigma, \mathrm{RH}$, and $\varepsilon_{\text {org }}$ can be explained by the dependence of the molecular area of the organic molecules on these parameters. When s, or equivalently the surface pressure, is considered as a function of molecular area (i.e., in $\pi$-molecular-area isotherms), organic-moleculespecific relationships are obtained that are independent of whether RH or $\varepsilon_{\text {org }}$ is responsible for the variation in the molecular area. The $\pi$-molecular-area isotherms from the droplets are used to determine critical molecular areas for each fatty acid. The $A_{0}$ value for oleic acid on droplets compared well to Langmuir trough measurements on macroscopic solutions, but the magnitude of $\pi$ values at high compression (i.e., small molecular areas) may be larger in the droplets. For myristic acid, the $A_{0}$ value on droplets compared best with macroscopic experiments in which dissolution was significant, i.e., when a fresh subphase was used.

When $\mathrm{NaCl}$ was coated with pure palmitic acid there was substantial suppression in water uptake observed. This was likely due to the formation of densely packed films through which water molecules could not efficiently permeate. The suppression disappeared when palmitic acid was mixed with oleic acid, indicating a decrease in packing density. For oleicacid-coated $\mathrm{NaCl}$ particles exposed to $\mathrm{O}_{3}$, the $\sigma$ values remain significantly lower than water at large $\varepsilon_{\text {org }}$ but may be slightly higher than pure oleic acid coatings. Overall, chemical changes due to oxidation of oleic acid by $\mathrm{O}_{3}$ had minimal impact on the $\sigma$ depression.

Values of the critical supersaturation were also quantified by a $\mathrm{CCN}$ counter for comparison to the observations made at $\mathrm{RH}$ values just below activation. Despite the large reductions in $\sigma$ observed at RH values just below $s_{\mathrm{c}}$, the measured $s_{\mathrm{c}}$ values indicate that the fatty acids have minimal impact on the ultimate activation into cloud droplets. This is because the additional growth as the RH increases to $s_{\mathrm{c}}$ causes the molecular area to rapidly increase above $A_{0}$, limiting the impact on activation. However, $\sigma$ has a large effect on the trajectory of activation by enhancing droplet sizes when $\mathrm{RH}$ is $<s_{\mathrm{c}}$.

The film model of Ruehl et al. (2016) was used to theoretically explore what properties surface-active organic compounds must have to have a substantial impact on $\mathrm{CCN}$ activation, and not just on the $\sigma$ at $\mathrm{RH}$ values very close to (yet below) $s_{\mathrm{c}}$. We find that it is theoretically possible for surface-active organics to have a substantial impact on CCN activation efficiency, even though this was not the case for 
the fatty acids here. In particular, the model $s_{\mathrm{c}}$ and consequently $\kappa_{\text {app }}$ are most sensitive to variations in the organic compound molecular volume ( $v_{\text {org }}$ ) and $A_{0}$ for $\mathrm{NaCl}$-coated particles with relatively large organic fractions. Further, we show that surface tension depression from surface-active organic molecules can serve to buffer $\kappa_{\text {app }}$ against changes in the organic-to-salt ratio when the $\varepsilon_{\text {org }}>0.5$. Overall, we conclude that surface-active organic molecules can have a substantial impact on CCN activation efficiency. However, the extent to which this will occur is strongly dependent upon the specific molecular properties of the organic molecules, and traditional surfactants (such as fatty acids) can actually have a negligible impact on $\mathrm{CCN}$ activation.

Data availability. All data associated with figures in this paper are archived at the DASH digital archive as part of the California Digital Library (Forestieri et al., 2018) with https://doi.org/10.25338/B84K5G.

\section{The Supplement related to this article is available online at https://doi.org/10.5194/acp-18-10985-2018- supplement.}

Author contributions. SDF, SMS, TMK and KF carried out experiments and analyzed data. CRR provided methodological guidance on experiments and analysis. SDF, THB and CDC conceived and oversaw the experiments. SDF and CDC led the writing of the paper with contributions from all authors.

Competing interests. The authors declare that they have no conflict of interest.

Acknowledgements. This study was funded by the Center for Aerosol Impacts on Climate and Environment (CAICE), a NSF Center for Chemical Innovation (CHE-1305427). The authors also thank Hansol Lee and Alexei Tivanski (University of Iowa) as well as Michael Vermeuel (UW Madison) for their input and support for this project.

Edited by: Annele Virtanen

Reviewed by: three anonymous referees

\section{References}

Adamson, A. W. and Gast, A. P.: Physical chemistry of surfaces, 1967.

Albrecht, O., Matsuda, H., Eguchi, K., and Nakagiri, T.: The dissolution of myristic acid monolayers in water, Thin Solid Films, 338, 252-264, 1999.

Asa-Awuku, A., Engelhart, G., Lee, B., Pandis, S. N., and Nenes, A.: Relating CCN activity, volatility, and droplet growth kinetics of $\beta$-caryophyllene secondary organic aerosol, Atmos.
Chem. Phys., 9, 795-812, https://doi.org/10.5194/acp-9-7952009, 2009.

Broekhuizen, K., Kumar, P. P., and Abbatt, J.: Partially soluble organics as cloud condensation nuclei: Role of trace soluble and surface active species, Geophys. Res. Lett., 31, L01107, https://doi.org/10.1029/2003GL018203, 2004.

Broekhuizen, K., Chang, R. Y. W., Leaitch, W. R., Li, S. M., and Abbatt, J. P. D.: Closure between measured and modeled cloud condensation nuclei $(\mathrm{CCN})$ using size-resolved aerosol compositions in downtown Toronto, Atmos. Chem. Phys., 6, 2513-2524, https://doi.org/10.5194/acp-6-2513-2006, 2006.

Cappa, C. D., Lovejoy, E. R., and Ravishankara, A. R.: Evaporation Rates and Vapor Pressures of the Even-Numbered C8C18 Monocarboxylic Acids, J. Phys. Chem. A, 112, 3959-3964, https://doi.org/10.1021/jp710586m, 2008.

Cochran, R. E., Laskina, O., Jayarathne, T., Laskin, A., Laskin, J., Lin, P., Sultana, C., Lee, C., Moore, K. A., and Cappa, C. D. Analysis of organic anionic surfactants in fine and coarse fractions of freshly emitted sea spray aerosol, Environ. Sci. Technol., 50, 2477-2486, https://doi.org/10.1021/acs.est.5b04053, 2016.

Cochran, R. E., Laskina, O., Trueblood, J. V., Estillore, A. D., Morris, H. S., Jayarathne, T., Sultana, C. M., Lee, C., Lin, P., and Laskin, J.: Molecular Diversity of Sea Spray Aerosol Particles: Impact of Ocean Biology on Particle Composition and Hygroscopicity, Chem, 2, 655-667, https://doi.org/10.1016/j.chempr.2017.03.007, 2017.

Collins, D. B., Bertram, T. H., Sultana, C. M., Lee, C., Axson, J. L., and Prather, K. A.: Phytoplankton blooms weakly influence the cloud forming ability of sea spray aerosol, Geophys. Res. Lett., 43, 9975-9983, https://doi.org/10.1002/2016gl069922, 2016.

Davies, J. F., Miles, R. E., Haddrell, A. E., and Reid, J. P.: Influence of organic films on the evaporation and condensation of water in aerosol, P. Natl. Acad. Sci., 110, 8807-8812, https://doi.org/10.1073/pnas.1305277110, 2013.

Deane, G. B., Cochran, R. E., Jayarathne, T., Rusch, L., Sultana, C. M., Lee, C., Tivanski, A. V., Cappa, C. D., Bertram, T. H., Prather, K. A., Grassian, V. H., and Stone, E. A.: Size-dependent transfer of organic matter to nascent sea spray aerosol, submitted, 2018.

Duplissy, J., Gysel, M., Alfarra, M. R., Dommen, J., Metzger, A., Prevot, A. S. H., Weingartner, E., Laaksonen, A., Raatikainen, T., Good, N., Turner, S. F., McFiggans, G., and Baltensperger, U.: Cloud forming potential of secondary organic aerosol under near atmospheric conditions, Geophys. Res. Lett., 35, L03818, https://doi.org/10.1029/2007GL031075, 2008.

Facchini, M. C., Mircea, M., Fuzzi, S., and Charlson, R. J.: Cloud albedo enhancement by surface-active organic solutes in growing droplets, Nature, 401, 257-259, https://doi.org/10.1038/45758, 1999.

Farmer, D. K., Cappa, C. D., and Kreidenweis, S. M.: Atmospheric Processes and Their Controlling Influence on Cloud Condensation Nuclei Activity, Chem. Rev., 115, 4199-4217, https://doi.org/10.1021/cr5006292, 2015.

Feher, A., Collins, F., and Healy, T.: Mixed monolayers of simple saturated and unsaturated fatty acids, Aust. J. Chem., 30, 511519, https://doi.org/10.1071/CH9770511, 1977.

Forestieri, S., Staudt, S., Kuborn, T., Ruehl, C., Bertram, T., and Cappa C.: Water uptake, cloud condensation nuclei and surface 
tension: results from the MadFACTS campaign, available at: https://doi.org/10.25338/B84K5G, 2018.

Fuentes, E., Coe, H., Green, D., and McFiggans, G.: On the impacts of phytoplankton-derived organic matter on the properties of the primary marine aerosol - Part 2: Composition, hygroscopicity and cloud condensation activity, Atmos. Chem. Phys., 11, 25852602, https://doi.org/10.5194/acp-11-2585-2011, 2011.

Giordano, M. R., Short, D. Z., Hosseini, S., Lichtenberg, W., and Asa-Awuku, A. A.: Changes in Droplet Surface Tension Affect the Observed Hygroscopicity of Photochemically Aged Biomass Burning Aerosol, Environ. Sci. Technol., 47, 1098010986, https://doi.org/10.1021/es401867j, 2013.

Good, N., Topping, D. O., Allan, J. D., Flynn, M., Fuentes, E., Irwin, M., Williams, P. I., Coe, H., and McFiggans, G.: Consistency between parameterisations of aerosol hygroscopicity and CCN activity during the RHaMBLe discovery cruise, Atmos. Chem. Phys., 10, 3189-3203, https://doi.org/10.5194/acp10-3189-2010, 2010a.

Good, N., Topping, D. O., Duplissy, J., Gysel, M., Meyer, N. K., Metzger, A., Turner, S. F., Baltensperger, U., Ristovski, Z., Weingartner, E., Coe, H., and McFiggans, G.: Widening the gap between measurement and modelling of secondary organic aerosol properties?, Atmos. Chem. Phys., 10, 2577-2593, https://doi.org/10.5194/acp-10-2577-2010, 2010b.

Gray Bé, A., Upshur, M. A., Liu, P., Martin, S. T., Geiger, F. M., and Thomson, R. J.: Cloud Activation Potentials for Atmospheric $\alpha$-Pinene and $\beta$-Caryophyllene Ozonolysis Products, ACS Central Science, 3, 715-725, https://doi.org/10.1021/acscentsci.7b00112, 2017.

Griffith, E. C., Adams, E. M., Allen, H. C., and Vaida, V.: Hydrophobic collapse of a stearic acid film by adsorbed 1phenylalanine at the air-water interface, J. Phys. Chem. B, 116, 7849-7857, https://doi.org/10.1021/jp303913e, 2012.

Hearn, J. D. and Smith, G. D.: Kinetics and Product Studies for Ozonolysis Reactions of Organic Particles Using Aerosol CIMS, J. Phys. Chem. A, 108, 10019-10029, https://doi.org/10.1021/jp0404145, 2004.

Hearn, J. D. and Smith, G. D.: Measuring rates of reaction in supercooled organic particles with implications for atmospheric aerosol, Phys. Chem. Chem. Phys., 7, 2549-2551, https://doi.org/10.1039/B506424D, 2005.

Henning, S., Rosenørn, T., D’Anna, B., Gola, A. A., Svenningsson, B., and Bilde, M.: Cloud droplet activation and surface tension of mixtures of slightly soluble organics and inorganic salt, Atmos. Chem. Phys., 5, 575-582, https://doi.org/10.5194/acp-5575-2005, 2005.

Inoue, T., Hisatsugu, Y., Ishikawa, R., and Suzuki, M.: Solidliquid phase behavior of binary fatty acid mixtures: 2 . Mixtures of oleic acid with lauric acid, myristic acid, and palmitic acid, Chem. Phys. Lipids, 127, 161-173, https://doi.org/10.1016/j.chemphyslip.2003.10.013, 2004.

Jeffers, P. M. and Daen, J.: Studies on Spreading, Collapse, and Temperature and Compression Rate Effects on Monolayers of $\alpha$, ı-Dicarboxylic Acids1a, J. Phys. Chem., 69, 2368-2373, https://doi.org/10.1021/j100891a042, 1965.

Jurányi, Z., Gysel, M., Weingartner, E., DeCarlo, P. F., Kammermann, L., and Baltensperger, U.: Measured and modelled cloud condensation nuclei number concentration at the high alpine site Jungfraujoch, Atmos. Chem. Phys., 10, 7891-7906, https://doi.org/10.5194/acp-10-7891-2010, 2010.

Kanicky, J. R. and Shah, D.: Effect of Degree, Type, and Position of Unsaturation on the $\mathrm{pKa}$ of LongChain Fatty Acids, J. Colloid Interf. Sci., 256, 201-207, https://doi.org/10.1006/jcis.2001.8009, 2002.

Katrib, Y., Martin, S. T., Hung, H.-M., Rudich, Y., Zhang, H., Slowik, J. G., Davidovits, P., Jayne, J. T., and Worsnop, D. R.: Products and mechanisms of ozone reactions with oleic acid for aerosol particles having core- shell morphologies, J. Phys. Chem. A, 108, 6686-6695, https://doi.org/10.1021/jp049759d, 2004.

Knopf, D. A., Anthony, L. M., and Bertram, A. K.: Reactive uptake of $\mathrm{O}_{3}$ by multicomponent and multiphase mixtures containing oleic acid, J. Phys. Chem. A, 109, 5579-5589, https://doi.org/10.1021/jp0512513, 2005.

Kuwata, M., Shao, W., Lebouteiller, R., and Martin, S. T.: Classifying organic materials by oxygen-to-carbon elemental ratio to predict the activation regime of Cloud Condensation Nuclei (CCN), Atmos. Chem. Phys., 13, 5309-5324, https://doi.org/10.5194/acp-13-5309-2013, 2013.

Lee, B. H., Lopez-Hilfiker, F. D., Mohr, C., Kurtén, T., Worsnop, D. R., and Thornton, J. A.: An Iodide-Adduct HighResolution Time-of-Flight Chemical-Ionization Mass Spectrometer: Application to Atmospheric Inorganic and Organic Compounds, Environ. Sci. Technol., 48, 6309-6317, https://doi.org/10.1021/es500362a, 2014.

Lee, H. D., Estillore, A. D., Morris, H. S., Ray, K. K., Alejandro, A., Grassian, V. H., and Tivanski, A. V.: Direct Surface Tension Measurements of Individual Sub-Micrometer Particles Using Atomic Force Microscopy, J. Phys. Chem. A, 121, 82968305, https://doi.org/10.1021/acs.jpca.7b04041, 2017.

Li, Z., Williams, A. L., and Rood, M. J.: Influence of Soluble Surfactant Properties on the Activation of Aerosol Particles Containing Inorganic Solute, J. Atmos. Sci., 55, 1859-1866, https://doi.org/10.1175/15200469(1998)055<1859:iosspo>2.0.co;2, 1998.

Lovrić, J., Duflot, D., Monnerville, M., Toubin, C., and Briquez, S.: Water-Induced Organization of Palmitic Acid at the Surface of a Model Sea Salt Particle: A Molecular Dynamics Study, J. Phys. Chem. A, 120, 10141-10149, https://doi.org/10.1021/acs.jpca.6b07792, 2016.

Mao, G., VanWyck, D., Xiao, X., Mack Correa, M. C., Gunn, E., Flach, C. R., Mendelsohn, R., and Walters, R. M.: Oleic Acid Disorders Stratum Corneum Lipids in Langmuir Monolayers, Langmuir, 29, 4857-4865, https://doi.org/10.1021/la4002384, 2013.

McNeill, V. F., Yatavelli, R. L. N., Thornton, J. A., Stipe, C. B., and Landgrebe, O.: Heterogeneous $\mathrm{OH}$ oxidation of palmitic acid in single component and internally mixed aerosol particles: vaporization and the role of particle phase, Atmos. Chem. Phys., 8, 5465-5476, https://doi.org/10.5194/acp-8-5465-2008, 2008.

Mikhailov, E., Vlasenko, S., Niessner, R., and Pöschl, U.: Interaction of aerosol particles composed of protein and saltswith water vapor: hygroscopic growth and microstructural rearrangement, Atmos. Chem. Phys., 4, 323-350, https://doi.org/10.5194/acp-4323-2004, 2004.

Mircea, M., Facchini, M. C., Decesari, S., Fuzzi, S., and Charlson, R. J.: The influence of the organic aerosol component on $\mathrm{CCN}$ supersaturation spectra for different aerosol 
types, Tellus Ser. B-Chem. Phys. Meteorol., 54, 74-81, https://doi.org/10.1034/j.1600-0889.2002.00256.x, 2002.

Mircea, M., Facchini, M. C., Decesari, S., Cavalli, F., Emblico, L., Fuzzi, S., Vestin, A., Rissler, J., Swietlicki, E., Frank, G., Andreae, M. O., Maenhaut, W., Rudich, Y., and Artaxo, P.: Importance of the organic aerosol fraction for modeling aerosol hygroscopic growth and activation: a case study in the Amazon Basin, Atmos. Chem. Phys., 5, 3111-3126, https://doi.org/10.5194/acp5-3111-2005, 2005.

Mochida, M., Umemoto, N., Kawamura, K., Lim, H.-J., and Turpin, B. J.: Bimodal size distributions of various organic acids and fatty acids in the marine atmosphere: Influence of anthropogenic aerosols, Asian dusts, and sea spray off the coast of East Asia, J. Geophys. Res.-Atmos., 112, D15209, https://doi.org/10.1029/2006JD007773, 2007.

Moore, R. H., Ingall, E. D., Sorooshian, A., and Nenes, A.: Molar mass, surface tension, and droplet growth kinetics of marine organics from measurements of CCN activity, Geophys. Res. Lett., 35, L07801, https://doi.org/10.1029/2008GL033350, 2008.

Murray, B. S. and Nelson, P. V.: A Novel Langmuir Trough for Equilibrium and Dynamic Measurements on Air-Water and Oil-Water Monolayers, Langmuir, 12, 5973-5976, https://doi.org/10.1021/la960748o, 1996.

Nguyen, Q. T., Kjær, K. H., Kling, K. I., Boesen, T., and Bilde, M.: Impact of fatty acid coating on the CCN activity of sea salt particles, Tellus B: Chemical and Physical Meteorology, 69, 1304064, https://doi.org/10.1080/16000889.2017.1304064, 2017.

Noziere, B., Baduel, C., and Jaffrezo, J.-L.: The dynamic surface tension of atmospheric aerosol surfactants reveals new aspects of cloud activation, Nat. Commun., 5, 3335, https://doi.org/10.1038/ncomms4335, 2014.

Ocko, B. M., Kelley, M. S., Nikova, A. T., and Schwartz, D. K.: Structure and Phase Behavior of Mixed Monolayers of Saturated and Unsaturated Fatty Acids, Langmuir, 18, 9810-9815, https://doi.org/10.1021/la026079y, 2002.

O’Dowd, C. D., Facchini, M. C., Cavalli, F., Ceburnis, D., Mircea, M., Decesari, S., Fuzzi, S., Yoon, Y. J., and Putaud, J. P.: Biogenically driven organic contribution to marine aerosol, Nature, 431, 676-680, https://doi.org/10.1038/nature02959, 2004b.

Ovadnevaite, J., Ceburnis, D., Martucci, G., Bialek, J., Monahan, C., Rinaldi, M., Facchini, M. C., Berresheim, H., Worsnop, D. R., and O'Dowd, C.: Primary marine organic aerosol: A dichotomy of low hygroscopicity and high CCN activity, Geophys. Res. Lett., 38, L21806, https://doi.org/10.1029/2011GL048869, 2011.

Ovadnevaite, J., Zuend, A., Laaksonen, A., Sanchez, K. J., Roberts, G., Ceburnis, D., Decesari, S., Rinaldi, M., Hodas, N., Facchini, M. C., Seinfeld, J. H., and O'Dowd, C.: Surface tension prevails over solute effect in organic-influenced cloud droplet activation, Nature, 546, 637-641, https://doi.org/10.1038/nature22806, 2017.

Petters, M. and Kreidenweis, S.: A single parameter representation of hygroscopic growth and cloud condensation nucleus activity, Atmos. Chem. Phys., 7, 1961-1971, https://doi.org/10.5194/acp7-1961-2007, 2007.

Petters, M. D. and Kreidenweis, S. M.: A single parameter representation of hygroscopic growth and cloud condensation nucleus activity - Part 3: Including surfactant partitioning, Atmos. Chem. Phys., 13, 1081-1091, https://doi.org/10.5194/acp13-1081-2013, 2013.
Petters, S. S. and Petters, M. D.: Surfactant effect on cloud condensation nuclei for two-component internally mixed aerosols, J. Geophys. Res.-Atmos., 121, 1878-1895, https://doi.org/10.1002/2015JD024090, 2016.

Petters, M., Kreidenweis, S., and Ziemann, P.: Prediction of cloud condensation nuclei activity for organic compounds using functional group contribution methods, Geosci. Model Dev., 9, 111124, https://doi.org/10.5194/gmd-9-111-2016, 2016.

Prisle, N. L., Raatikainen, T., Laaksonen, A., and Bilde, M.: Surfactants in cloud droplet activation: mixed organicinorganic particles, Atmos. Chem. Phys., 10, 5663-5683, https://doi.org/10.5194/acp-10-5663-2010, 2010.

Prisle, N. L., Dal Maso, M., and Kokkola, H.: A simple representation of surface active organic aerosol in cloud droplet formation, Atmos. Chem. Phys., 11, 4073-4083, https://doi.org/10.5194/acp-11-4073-2011, 2011.

Raatikainen, T., Nenes, A., Seinfeld, J. H., Morales, R., Moore, R. H., Lathem, T. L., Lance, S., Padró, L. T., Lin, J. J., and Cerully, K. M.: Worldwide data sets constrain the water vapor uptake coefficient in cloud formation, P. Natl. Acad. Sci., 110, 3760-3764, https://doi.org/10.1073/pnas.1219591110, 2013.

Rabinovitch, W., Robertson, R., and Mason, S.: Relaxation of surface pressure and collapse of unimolecular films of stearic acid, Canad. J. Chem., 38, 1881-1890, https://doi.org/10.1139/v60253, 1960.

Rasmussen, B. B., Nguyen, Q. T., Kristensen, K., Nielsen, L. S., and Bilde, M.: What controls volatility of sea spray aerosol? Results from laboratory studies using artificial and real seawater samples, J. Aerosol Sci., 107, 134-141, https://doi.org/10.1016/j.jaerosci.2017.02.002, 2017.

Roberts, G. and Nenes, A.: A continuous-flow streamwise thermal-gradient $\mathrm{CCN}$ chamber for atmospheric measurements, Aerosol Sci. Technol., 39, 206-221, https://doi.org/10.1080/027868290913988, 2005.

Ruehl, C. R. and Wilson, K. R.: Surface Organic Monolayers Control the Hygroscopic Growth of Submicrometer Particles at High Relative Humidity, J. Phys. Chem. A, 118, 3952-3966, https://doi.org/10.1021/jp502844g, 2014.

Ruehl, C. R., Chuang, P. Y., and Nenes, A.: Aerosol hygroscopicity at high (99 to $100 \%$ ) relative humidities, Atmos. Chem. Phys., 10, 1329-1344, https://doi.org/10.5194/acp-101329-2010, 2010.

Ruehl, C. R., Chuang, P. Y., Nenes, A., Cappa, C. D., Kolesar, K. R., and Goldstein, A. H.: Strong evidence of surface tension reduction in microscopic aqueous droplets, Geophys. Res. Lett., 39, L23801, https://doi.org/10.1029/2012g1053706, 2012.

Ruehl, C. R., Davies, J. F., and Wilson, K. R.: An interfacial mechanism for cloud droplet formation on organic aerosols, Science, 351, 1447-1450, https://doi.org/10.1126/science.aad4889, 2016.

Sareen, N., Schwier, A. N., Lathem, T. L., Nenes, A., and McNeill, V. F.: Surfactants from the gas phase may promote cloud droplet formation, P. Natl. Acad. Sci., 110, 2723-2728, https://doi.org/10.1073/pnas.1204838110, 2013.

Schmitt-Kopplin, P., Liger-Belair, G., Koch, B. P., Flerus, R., Kattner, G., Harir, M., Kanawati, B., Lucio, M., Tziotis, D., Hertkorn, N., and Gebefügi, I.: Dissolved organic matter in sea spray: a transfer study from marine surface water to aerosols, Biogeosciences, 9, 1571-1582, https://doi.org/10.5194/bg-91571-2012, 2012. 
Schwier, A., Sareen, N., Lathem, T., Nenes, A., and McNeill, V.: Ozone oxidation of oleic acid surface films decreases aerosol cloud condensation nuclei activity, J. Geophys. Res.-Atmos., 116, D16202, https://doi.org/10.1029/2010JD015520, 2011.

Schwier, A., Mitroo, D., and McNeill, V. F.: Surface tension depression by low-solubility organic material in aqueous aerosol mimics, Atmos. Environ., 54, 490-495, https://doi.org/10.1016/j.atmosenv.2012.02.032, 2012.

Seoane, R., Miñones, J., Conde, O., Miñones, J., Casas, M., and Iribarnegaray, E.: Thermodynamic and Brewster Angle Microscopy Studies of Fatty Acid/Cholesterol Mixtures at the Air/Water Interface, J. Phys. Chem. B, 104, 7735-7744, https://doi.org/10.1021/jp001133+, 2000.

Shaloski, M. A., Gord, J. R., Staudt, S., Quinn, S. L., Bertram, T. H., and Nathanson, G. M.: Reactions of N2O5 with Salty and Surfactant-Coated Glycerol: Interfacial Conversion of $\mathrm{Br}^{-}$ to $\mathrm{Br}_{2}$ Mediated by Alkylammonium Cations, J. Phys. Chem. A, 121, 3708-3719, https://doi.org/10.1021/acs.jpca.7b02040, 2017.

Smith, R. D. and Berg, J. C.: The collapse of surfactant monolayers at the air-water interface, J. Colloid Interf. Sci., 74, 273-286, https://doi.org/10.1016/0021-9797(80)90190-3, 1980.

Sorjamaa, R., Svenningsson, B., Raatikainen, T., Henning, S., Bilde, M., and Laaksonen, A.: The role of surfactants in Köhler theory reconsidered, Atmos. Chem. Phys., 4, 2107-2117, https://doi.org/10.5194/acp-4-2107-2004, 2004.

Takahama, S. and Russell, L.: A molecular dynamics study of water mass accommodation on condensed phase water coated by fatty acid monolayers, J. Geophys. Res.-Atmos., 116, D02203, https://doi.org/10.1029/2010JD014842, 2011.

Tang, C. Y., Huang, Z., and Allen, H. C.: Interfacial water structure and effects of $\mathrm{Mg}^{2+}$ and $\mathrm{Ca}^{2+}$ binding to the $\mathrm{COOH}$ headgroup of a palmitic acid monolayer studied by sum frequency spectroscopy, J. Phys. Chem. B, 115, 34-40, https://doi.org/10.1021/jp1062447, 2010.
Topping, D., Barley, M., Bane, M. K., Higham, N., Aumont, B., Dingle, N., and McFiggans, G.: UManSysProp v1.0: an online and open-source facility for molecular property prediction and atmospheric aerosol calculations, Geosci. Model Dev., 9, 899914, https://doi.org/10.5194/gmd-9-899-2016, 2016.

Voss, L. F., Bazerbashi, M. F., Beekman, C. P., Hadad, C. M., and Allen, H. C.: Oxidation of oleic acid at air/liquid interfaces, J. Geophys. Res.-Atmos., 112, D06209, https://doi.org/10.1029/2006JD007677, 2007.

Wex, H., Petters, M. D., Carrico, C. M., Hallbauer, E., Massling, A., McMeeking, G. R., Poulain, L., Wu, Z., Kreidenweis, S. M., and Stratmann, F.: Towards closing the gap between hygroscopic growth and activation for secondary organic aerosol: Part 1 - Evidence from measurements, Atmos. Chem. Phys., 9, 3987-3997, https://doi.org/10.5194/acp-9-3987-2009, 2009.

Wüstneck, R., Perez-Gil, J., Wüstneck, N., Cruz, A., Fainerman, V. B., and Pison, U.: Interfacial properties of pulmonary surfactant layers, Advances in Colloid and Interface Science, 117, 33-58, https://doi.org/10.1016/j.cis.2005.05.001, 2005.

Yakobi-Hancock, J. D., Ladino, L. A., Bertram, A. K., Huffman, J. A., Jones, K., Leaitch, W. R., Mason, R. H., Schiller, C. L., Toom-Sauntry, D., Wong, J. P. S., and Abbatt, J. P. D.: CCN activity of size-selected aerosol at a Pacific coastal location, Atmos. Chem. Phys., 14, 12307-12317, https://doi.org/10.5194/acp-1412307-2014, 2014.

Zelenyuk, A., Cai, Y., and Imre, D.: From Agglomerates of Spheres to Irregularly Shaped Particles: Determination of Dynamic Shape Factors from Measurements of Mobility and Vacuum Aerodynamic Diameters, Aerosol Sci. Technol., 40, 197217, https://doi.org/10.1080/02786820500529406, 2006. 